OPEN ACCESS

Edited by:

Matthew Zibelman,

Fox Chase Cancer Center,

United States

Reviewed by:

Riccardo Tellini,

Careggi University Hospital, Italy Itay Aharon Sternberg,

Meir Medical Center, Israel

*Correspondence: Bo Fan

fanbo@dmu.edu.cn

Guoyu Wu

wuguoyu031219@sina.com

Xiancheng $\mathrm{Li}$

xianchengli@sina.cn

${ }^{t}$ These authors have contributed equally to this work

Specialty section: This article was submitted to Genitourinary Oncology, a section of the journal

Frontiers in Oncology

Received: 25 November 2020 Accepted: 30 June 2021

Published: 19 July 2021

Citation:

Fan B, Mohammed A, Huang $Y$, Luo H, Zhang H, Tao S, Xu W, Liu Q, $H$ e $T$, Jin $H$, Sun $M$, Sun $M$, Yun $Z$, Zhao R, Wu G and Li X (2021) Can Aspirin Use Be Associated With the Risk or Prognosis of Bladder Cancer? A Case-Control Study and Meta-analytic Assessment.

Front. Oncol. 11:633462. doi: 10.3389/fonc.2021.633462

\section{Can Aspirin Use Be Associated With the Risk or Prognosis of Bladder Cancer? A Case-Control Study and Meta-analytic Assessment}

Bo Fan ${ }^{1 *+}$, Alradhi Mohammed ${ }^{1+}$, Yuanbin Huang ${ }^{1+}$, Hong Luo ${ }^{2}$, Hongxian Zhang ${ }^{1}$, Shenghua Tao ${ }^{1}$, Weijiao $\mathrm{Xu}^{2}$, Qian Liu ${ }^{3}$, Tao He ${ }^{1}$, Huidan Jin ${ }^{4}$, Mengfan Sun ${ }^{5}$, Man Sun ${ }^{2}$, Zhifei Yun ${ }^{2}$, Rui Zhao ${ }^{5}$, Guoyu $W u^{6 *}$ and Xiancheng $\mathrm{Li}^{1 *}$

\footnotetext{
${ }^{1}$ Department of Urology, Second Affiliated Hospital of Dalian Medical University, Dalian, China, ${ }^{2}$ Clinical Medicine, Dalian Medical University, Dalian, China, ${ }^{3}$ Medical Imaging, Dalian Medical University, Dalian, China, ${ }^{4}$ Department of Anaesthesiology, Fifth Affiliated Hospital of Sun Yat-Sen University, Zhuhai, China, ${ }^{5}$ Department of Pharmacy, Zhongshan College of Dalian Medical University, Dalian, China, ${ }^{6}$ Department of Pharmacy, First Affiliated Hospital of Dalian Medical University, Dalian, China
}

Aspirin, widely used to prevent cardiovascular disease, had been linked to the incidence of bladder cancer (BCa). Existing studies focusing on Chinese populations are relatively rare, especially for Northeast China. Meanwhile, relevant studies on the effects of aspirin on the occurrence or prognosis of $\mathrm{BCa}$ are inconsistent or even controversial. First, in the case control study, logistic regression analysis was used to investigate the association between aspirin intake and risk of BCa including 1121 patients with BCa and the 2242 controls. Subsequently, Kaplan-Meier curve and Cox regression analyses were applied to explore the association between aspirin intake and clinicopathological factors which may predict overall survival (OS) and recurrence-free survival (RFS) of BCa patients. Finally, we quantificationally combined the results with those from the published literature evaluating aspirin intake and its effects on the occurrence, outcome of surgery and prognosis of BCa by meta-analysis up to May 1, 2021.Our case-control study demonstrated that the regular use of aspirin was not associated with a reduced incidence of $\mathrm{BCa}(P=0.175)$. Stratified analyses of sex showed that aspirin intake did not lead to a lower risk of BCa in female patients $(P=0.063)$. However, the male population who regularly took aspirin had a lower incidence of $\mathrm{BCa}(\mathrm{OR}=0.748,95 \% \mathrm{Cl}=0.584$ $0.958, P=0.021)$. Subgroup analyses stratified by smoking found a significant reduction in the risk of $\mathrm{BCa}$ in current smokers with aspirin intake (OR=0.522, 95\% $\mathrm{Cl}=0.342-0.797$, $P=0.002)$. In terms of prognosis of $\mathrm{BCa}$, patients with a history of aspirin intake did not had a markedly longer OS or RFS than those with no history of aspirin intake by Kaplan-Meier curves. Stratified analysis by sex showed no correlation between aspirin intake and the recurrence or survival of $\mathrm{BCa}$ for either male or female patients. However, in people younger than 68, aspirin intake seemed to have prolonged effects for overall survival ( $\mathrm{HR}=3.876$; 95\% Cl=1.326-11.325, $P=0.019)$. Then, we performed a meta-analysis and the combined results from 19 articles and our study involving more than 39524 BCa cases 
indicated that aspirin intake was not associated with the occurrence of BCa ( $P=0.671)$. Subgroup analysis by whether regular use of aspirin, by the mean duration of use of aspirin, by sex, by smoking exposure, by research region and by study type also supported the above results. In terms of the impact of aspirin intake on the prognosis of patients with $\mathrm{BCa}, 11$ articles and our study involving 8825 BCa cases were eligible. The combined results showed that patients with aspirin intake did not have significantly influence on survival, recurrence, progression and metastasis than those without aspirin intake. On the whole, both our retrospective study and literature meta-analysis suggested a lack of a strong relevant association between the use of aspirin and the incidence or prognosis of $\mathrm{BCa}$. Thus, additional long-term follow-up prospective research is warranted to clarify the association of aspirin with $\mathrm{BCa}$ incidence and prognosis.

Keywords: urinary bladder neoplasms, aspirin, risk, prognosis, case-control, meta-analysis

\section{BACKGROUND}

Bladder cancer $(\mathrm{BCa})$ is the 11 th most common cancer in the world. The global age-standardized incidence rate per 100,000 persons/year is 2.2 for women and 9.0 for men $(1,2)$. According to the National Cancer Institute, the estimated numbers of new BCa cases and deaths in the USA alone (2014) will be 74,690 and 15,580 , respectively $(3,4)$. In China, the incidence and mortality rates have increased gradually in the past few years. According to the National Central Cancer Registry (NCCR) of China 2015 annual report, the overall incidence of $\mathrm{BCa}$ was $7.68 / 10^{5}(5,6)$. Among patients with superficial or non-muscle invasive tumors after transurethral resection or perfusion therapy, $70 \%$ would experience recurrence, and $10 \%$ to $20 \%$ would show progression to muscle-invasive tumors $(7,8)$. Due to the unfavorable prognosis of muscle-invasive cancer, the treatment involves multiple modalities, including radical surgery, radiotherapy, and chemotherapy. However, nearly half of these patients develop metastases and die within 3 years $(7,9)$. The occurrence or recurrence of $\mathrm{BCa}$ is a molecular biological change or process that is effected by occupational factors, nonoccupational factors, and genomics and proteomics factors (10) Other non-occupational factors, including cigarette smoking (11), drinking water used for washing or cleaning drinking water used for washing or cleaning (12) the consumption of substances with nitrate and nitrite content (13), alcohol consumption (14), and special drug intake $(15,16)$, have also been associated with BCa but are less well established. Therefore, early detection strategies and prognosis monitoring are essential for reducing mortality from $\mathrm{BCa}$.

Aspirin, a typical non-steroidal anti-inflammatory drug, has been widely used for pain, fever and cardiovascular disease (17, 18) In recent years, a large accounts of studies have suggested that aspirin has a potential preventive effect in several types of cancers (18-20). The antitumor activity of aspirin is thought to be based mainly on two different mechanisms. First, aspirin may interfere with carcinogenesis by inhibiting the target of cyclooxygenase (COX), which is produced in response to inflammation and leads to angiogenesis and reduced apoptosis.
As one of isoforms of cyclooxygenase, the level of COX-2 may not only increase the malignant properties of $\mathrm{BCa}$ cells but also be related to high-grade and advanced-stage BCa patients (21, 22). Second, aspirin plays roles in promoting apoptosis or inhibiting the proliferation of tumor cells by interfering with the pathway independent of COX-2 as an anticancer agent. Aspirin inhibits the growth of PI3K mutant breast cancer by activating AMP-activated protein kinase (AMPK) and inhibiting mechanistic target of rapamycin complex 1 (mTORC1) signaling independent of COX-2 and IKK- $\beta / \mathrm{NF}-\kappa \mathrm{B}$ (23). Furthermore, aspirin inhibited the proliferation of neuroblastoma cells, upregulated $\mathrm{p} 21 \mathrm{Waf} 1$ and regulated $\mathrm{Rb} 1$ to promote differentiation through a Cox-independent mechanism (24).

Since aspirin has apparent preventive effects on other tumors, its role in $\mathrm{BCa}$ has also received attention. The findings of the impact of aspirin intake and the incidence and mortality of BCa have been inconclusive. Moreover, few studies on the relationship between aspirin intake and $\mathrm{BCa}$ in mainland China, especially in Northeast China. To explore whether the use of aspirin is associated with altered risk of $\mathrm{BCa}$, we conducted a case-control study by enrolling 1121 patients with BCa. To avoid bias from single-center study results, we further completed a meta-analysis of eligible literature by searching electronic journals or databases for documents before March 1, 2021. The connection between aspirin intake and the incidence and prognosis of $\mathrm{BCa}$ was investigated, which helps to further determine whether the use of aspirin has a preventive effect on $\mathrm{BCa}$. Our analysis provides a basis for further exploration of the role of aspirin in the future.

\section{MATERIALS AND METHODS}

\section{Retrospective Study \\ Study Population for Exploring the Association of Aspirin Intake and Risk of Bladder Cancer}

This study was approved by the institutional review committee of the Second Affiliated Hospital of Dalian Medical University. The study population consisted of 1121 bladder cancer cases with 
average age 68 years old, ranging from 49 to 84 years. The control group comprised of 2242 individuals without a bladder cancer diagnosis during the study period, which were hospitalized in the department of respiratory, gastroenterology, orthopedic surgery, dermatology, and cardiology, etc.

Patients in both groups underwent 1:2 matching based on sex, age, and follow-up period at the index date of each case. The possible risk factors for the occurrence of $\mathrm{BCa}$, including age, marital status, smoking status, alcohol use, aspirin use, metformin use, history of cardiovascular disease, history of cerebrovascular disease and history of diabetes were extracted from clinical history information.

\section{Study Population for Exploring Association of Aspirin Intake and Prognosis of Bladder Cancer}

1121 patients in the case group who were pathologically diagnosed with bladder cancer by pathological biopsy or surgical biopsy at the Second Affiliated Hospital of Dalian Medical University were included in the study. The clinical and pathological baseline data, including age, gender, histological grading, $\mathrm{T}$ stage, lymph node metastasis, distant metastasis, type of surgery were recorded. TMN staging and histological grading were determined according to the 2004 WHO/ISUP classification. Recurrence of bladder cancer is defined as visual and/or biopsy evidence of a tumor confirmed by cystoscopy or urine cytology.

\section{Assessment of Aspirin Use}

Aspirin users were defined as those who used at least $81 \mathrm{mg}$ aspirin daily at least twice a week for 1 month or more. Nonusers are subjects who had never used the drug or had used it for $<1$ month. The average daily dose of aspirin for each aspirin user was also obtained by dividing the cumulative dose of aspirin by the cumulative number of days of aspirin use. The indication for the use of aspirin (i.e., analgesic or cardiovascular disease, cerebrovascular disease prevention) was also recorded (25-27). Patients were stratified according to aspirin intake for most $(50 \%$ or more) of the interval between diagnosis and the date of the first tumor recurrence or last follow-up. The exclusion criteria were as follows: (1). Unable to obtain accurate medication records, demographic data, or patient characteristics. (2). Identification of a history of exposure to carcinogens. (3). Patients on clopidogrel, warfarin, or statins alone or in combination with other fibrin clotting inhibitors. (4). Aspirin use was contraindicated.

\section{Statistical Analysis}

SPSS version 13.0 (SPSS Inc., Chicago, USA) was used for analysis. The associations between aspirin intake and clinicopathological parameters were evaluated by the chisquare test. Continuous data and frequency data were analyzed by $t$ test and Fisher's exact test. When the independent variables were screened in order to investigate the risk factors for the occurrence of $\mathrm{BCa}$, adjusted odds ratios (ORs) or relative risks (RRs) and the corresponding 95\% confidence intervals (CIs) were calculated by univariate and multivariate logistic regression analysis. By univariate analysis, those with a significant $P$ value less than 0.05 in this test were included in the multivariate regression analysis. To evaluate the overall survival (OS) which was the interval from surgery to death and recurrence-free survival (RFS) which was the interval from surgery to intravesical recurrence in patients with $\mathrm{BCa}$, the Kaplan-Meier curve and log-rank test were used. After assessing clinicopathologic factors by univariate Cox regression model, statistically significant variables were put into multivariate Cox regression analysis to find independent prognostic factors for OS and RFS. After SPSS analysis, the $P$ value of the above parameters was obtained. A $P$-value less than 0.05 was considered statistically significant.

\section{Meta-Analysis Search Strategy}

The implementation of this meta-analysis was conducted based on the "Preferred Reporting Items for Systematic Reviews and Meta-Analyses" (PRISMA) guidelines. The PRISMA checklist was shown in Table 1. Our meta-analysis has been already registered of the review protocol on PROSPERO (CRD42021245411). The study retrieved articles from the PubMed, Embase, Ovid Medicine, Cochrane Library and Scopus databases published before May 1, 2021, to identify relevant studies evaluating aspirin intake and its effects on the occurrence and prognosis of $\mathrm{BCa}$ using the following medical subject headings that include all spelling variations: "bladder cancer" and "aspirin", "occurrence", "risk" and "prognosis", "survival" and "recurrence". Without national and linguistic restrictions, after reviewing the duplicate data, the two reviewers independently screened the titles and abstracts, excluding articles that were not associated with our research, reviews, and related animal experiments and maximizing data quality.

\section{Selection Criteria}

Studies satisfying the following criteria were included in our analysis: (1) the histologic type of the tumors was urothelial carcinoma of the bladder by histologic or pathologic examination; (2) the association between aspirin intake and the risk of $\mathrm{BCa}$ or prognosis of patients with $\mathrm{BCa}$ was investigated; and (3) sufficiency of data for the calculations of OR/RR/hazard ratio (HR), 95\% CI and $P$-value. Accordingly, the following exclusion criteria were applied: (1) studies in the form of reviews, letters to the editor, commentaries, or case reports that lacked original data; (2) molecular biology research that explored the impact of aspirin on cancer cell lines and animal models; and (3) studies in which the HR/OR/RR and its standard error could not be collected based on the given information.

\section{Data Extraction}

After the full-text evaluation, the two authors extracted the data separately for further qualitative and quantitative analysis to increase the authenticity of the data. For the selected articles, we extracted data from each study, including the first author, publication time, region, type of study, study period the number of participants and BCa cases, age, the usage of aspirin, $\mathrm{HR} / \mathrm{OR} / \mathrm{RR}$, and adjustment factors. 
TABLE 1 | PRISMA checklist.

\begin{tabular}{|c|c|c|c|}
\hline Section/topic & $\#$ & Checklist item & Reported on page \# \\
\hline \multicolumn{4}{|l|}{ TITLE } \\
\hline Title & 1 & Identify the report as a systematic review, meta-analysis, or both. & 1 \\
\hline \multicolumn{4}{|c|}{ 然 } \\
\hline Structured summary & 2 & $\begin{array}{l}\text { Provide a structured summary including, as applicable: background; objectives; data sources; study } \\
\text { eligibility criteria, participants, and interventions; study appraisal and synthesis methods; results; } \\
\text { limitations; conclusions and implications of key findings; systematic review registration number. }\end{array}$ & $1-2$ \\
\hline \multicolumn{4}{|c|}{ (2) } \\
\hline Rationale & 3 & Describe the rationale for the review in the context of what is already known. & 2 \\
\hline Objectives & 4 & $\begin{array}{l}\text { Provide an explicit statement of questions being addressed with reference to participants, interventions, } \\
\text { comparisons, outcomes, and study design (PICOS). }\end{array}$ & 2 \\
\hline \multicolumn{4}{|c|}{ 学 } \\
\hline $\begin{array}{l}\text { Protocol and } \\
\text { registration }\end{array}$ & 5 & $\begin{array}{l}\text { Indicate if a review protocol exists, if and where it can be accessed (e.g., Web address), and, if available, } \\
\text { provide registration information including registration number. }\end{array}$ & 3 \\
\hline Eligibility criteria & 6 & $\begin{array}{l}\text { Specify study characteristics (e.g., PICOS, length of follow-up) and report characteristics (e.g., years } \\
\text { considered, language, publication status) used as criteria for eligibility, giving rationale. }\end{array}$ & 3 \\
\hline Information sources & 7 & $\begin{array}{l}\text { Describe all information sources (e.g., databases with dates of coverage, contact with study authors to } \\
\text { identify additional studies) in the search and date last searched. }\end{array}$ & 3 \\
\hline Search & 8 & $\begin{array}{l}\text { Present full electronic search strategy for at least one database, including any limits used, such that it } \\
\text { could be repeated. }\end{array}$ & 3 \\
\hline Study selection & 9 & $\begin{array}{l}\text { State the process for selecting studies (i.e., screening, eligibility, included in systematic review, and, if } \\
\text { applicable, included in the meta-analysis). }\end{array}$ & 3 \\
\hline $\begin{array}{l}\text { Data collection } \\
\text { process }\end{array}$ & 10 & $\begin{array}{l}\text { Describe method of data extraction from reports (e.g., piloted forms, independently, in duplicate) and } \\
\text { any processes for obtaining and confirming data from investigators. }\end{array}$ & 3 \\
\hline Data items & 11 & $\begin{array}{l}\text { List and define all variables for which data were sought (e.g., PICOS, funding sources) and any } \\
\text { assumptions and simplifications made. }\end{array}$ & 3 \\
\hline $\begin{array}{l}\text { Risk of bias in } \\
\text { individual studies }\end{array}$ & 12 & $\begin{array}{l}\text { Describe methods used for assessing risk of bias of individual studies (including specification of whether } \\
\text { this was done at the study or outcome level), and how this information is to be used in any data } \\
\text { synthesis. }\end{array}$ & 5; Figure 1 \\
\hline Summary measures & 13 & State the principal summary measures (e.g., risk ratio, difference in means). & 5 \\
\hline Synthesis of results & 14 & $\begin{array}{l}\text { Describe the methods of handling data and combining results of studies, if done, including measures of } \\
\text { consistency }\left(\text { e.g., }\left.\right|^{2}\right) \text { for each meta-analysis. }\end{array}$ & 5 \\
\hline $\begin{array}{l}\text { Risk of bias across } \\
\text { studies }\end{array}$ & 15 & $\begin{array}{l}\text { Specify any assessment of risk of bias that may affect the cumulative evidence (e.g., publication bias, } \\
\text { selective reporting within studies). }\end{array}$ & 5 \\
\hline Additional analyses & 16 & $\begin{array}{l}\text { Describe methods of additional analyses (e.g., sensitivity or subgroup analyses, meta-regression), if } \\
\text { done, indicating which were pre-specified. }\end{array}$ & 5 \\
\hline \multicolumn{4}{|l|}{ RESULTS } \\
\hline Study selection & 17 & $\begin{array}{l}\text { Give numbers of studies screened, assessed for eligibility, and included in the review, with reasons for } \\
\text { exclusions at each stage, ideally with a flow diagram. }\end{array}$ & 8; Figure 2 \\
\hline Study characteristics & 18 & $\begin{array}{l}\text { For each study, present characteristics for which data were extracted (e.g., study size, PICOS, follow-up } \\
\text { period) and provide the citations. }\end{array}$ & 8, 9; Tables 7-9 \\
\hline $\begin{array}{l}\text { Risk of bias within } \\
\text { studies }\end{array}$ & 19 & Present data on risk of bias of each study and, if available, any outcome level assessment (see item 12). & 5; Figure 1 \\
\hline $\begin{array}{l}\text { Results of individual } \\
\text { studies }\end{array}$ & 20 & $\begin{array}{l}\text { For all outcomes considered (benefits or harms), present, for each study: (a) simple summary data for } \\
\text { each intervention group (b) effect estimates and confidence intervals, ideally with a forest plot. }\end{array}$ & $\begin{array}{l}9,10,12-17 \text {; Figures } \\
\mathbf{3}, \mathbf{5}-\mathbf{1 3}\end{array}$ \\
\hline Synthesis of results & 21 & Present results of each meta-analysis done, including confidence intervals and measures of consistency. & $\begin{array}{l}9, \mathbf{1 0}, 12-17 \text {; Figures } \\
\mathbf{3}, \mathbf{5}-\mathbf{1 3}\end{array}$ \\
\hline $\begin{array}{l}\text { Risk of bias across } \\
\text { studies }\end{array}$ & 22 & Present results of any assessment of risk of bias across studies (see Item 15). & $\begin{array}{l}9,10,12-17 \text {; Figures } \\
\mathbf{3}, \mathbf{5}-\mathbf{1 3}\end{array}$ \\
\hline Additional analysis & 23 & $\begin{array}{l}\text { Give results of additional analyses, if done (e.g., sensitivity or subgroup analyses, meta-regression [see } \\
\text { item 16]). }\end{array}$ & 9, 10, 12-17; Figure 4 \\
\hline \multicolumn{4}{|l|}{ DISCUSSION } \\
\hline $\begin{array}{l}\text { Summary of } \\
\text { evidence }\end{array}$ & 24 & $\begin{array}{l}\text { Summarize the main findings including the strength of evidence for each main outcome; consider their } \\
\text { relevance to key groups (e.g., healthcare providers, users, and policy makers). }\end{array}$ & 18,19 \\
\hline Limitations & 25 & $\begin{array}{l}\text { Discuss limitations at study and outcome level (e.g., risk of bias), and at review-level (e.g., incomplete } \\
\text { retrieval of identified research, reporting bias). }\end{array}$ & 19 \\
\hline Conclusions & 26 & $\begin{array}{l}\text { Provide a general interpretation of the results in the context of other evidence, and implications for future } \\
\text { research. }\end{array}$ & 19 \\
\hline \multicolumn{4}{|c|}{ 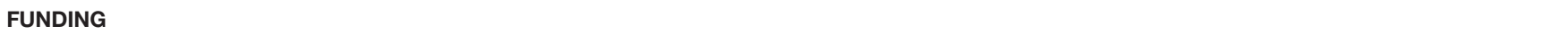 } \\
\hline Funding & 27 & $\begin{array}{l}\text { Describe sources of funding for the systematic review and other support (e.g., supply of data); role of } \\
\text { funders for the systematic review. }\end{array}$ & 20 \\
\hline
\end{tabular}




\section{Quality Assessment}

The quality assessment used the most recent version of the risk of bias tool recommended in the ROBINS-I checklist (28) for systematic reviews of interventions for the included studies. Our selected studies were assessed for bias due to confounding, selection bias, intervention measurement, missing data bias, outcome measurement, reporting bias, and other types of bias. As shown in Figure 1, the risk of bias of our meta-analyses measured by ROBINS-I framework for individual studies was generally low to moderate.

\section{Sensitivity Analysis}

Whether influential studies needed to be secondary for exclusion from our meta-analysis was determined by sensitivity analysis. The robustness of the pooled estimates with respect to the employed individual investigations was evaluated using the leave-one-out method based on the Q-test. Lower heterogeneity was determined after eliminating the indicated studies if the $P_{\mathrm{Q}}$ value $>0.05$. Conversely, low heterogeneity was calculated by removing a single study, indicating that the selected studies did not contribute to the heterogeneity of the overall meta-analysis.

\section{Statistical Analysis}

The Stata 12.0 statistical software package (Stata Corp, College Station, TX, USA) was used for all data analyses. We calculated the OR/RR/HR with a 95\% CI. The Q-test was used to assess the statistical heterogeneity and judge the $\mathrm{p}$ value qualitatively. The $\mathrm{I}^{2}$ value in the $\mathrm{I}^{2}$ test describes the proportion of the total variation due to heterogeneity rather than sampling errors, and $\mathrm{I}^{2}>50 \%$ or $P<0.05$ indicates a high degree of heterogeneity. The random-effects model was used; otherwise, there was no heterogeneity, and the fixed-effects model was used. The potential bias was assessed by a funnel plot and Egger's test, and when the funnel plot was symmetrically distributed, there was no significant bias. Conversely, if the funnel plot exhibits skewness and asymmetry, this indicated bias.
A

C

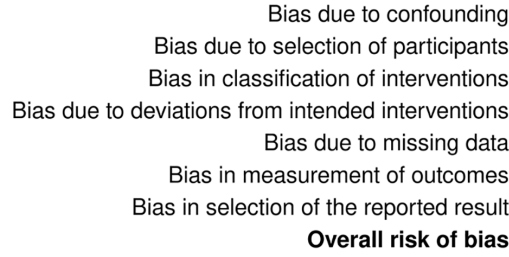

Bias due to confounding Bias due to selection of participants Bias in classification of interventions Bias due to deviations from intended interventions Bias due to missing data Bias in measurement of outcomes Bias in selection of the reported result Overall risk of bias

Bias due to confounding Bias due to selection of participants Bias in classification of interventions Bias due to deviations from intended interventions Bias due to missing data Bias in measurement of outcomes Bias in selection of the reported result Overall risk of bias

$$
0 \%
$$

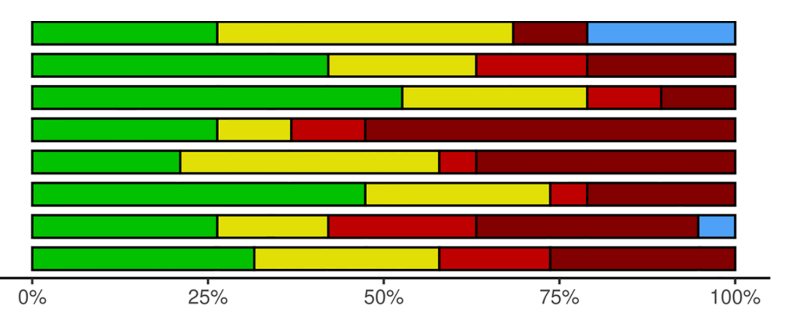

$\square$ Low risk $\square$ Moderate risk $\square$ Serious risk $\square$ Critical risk $\square$ No information
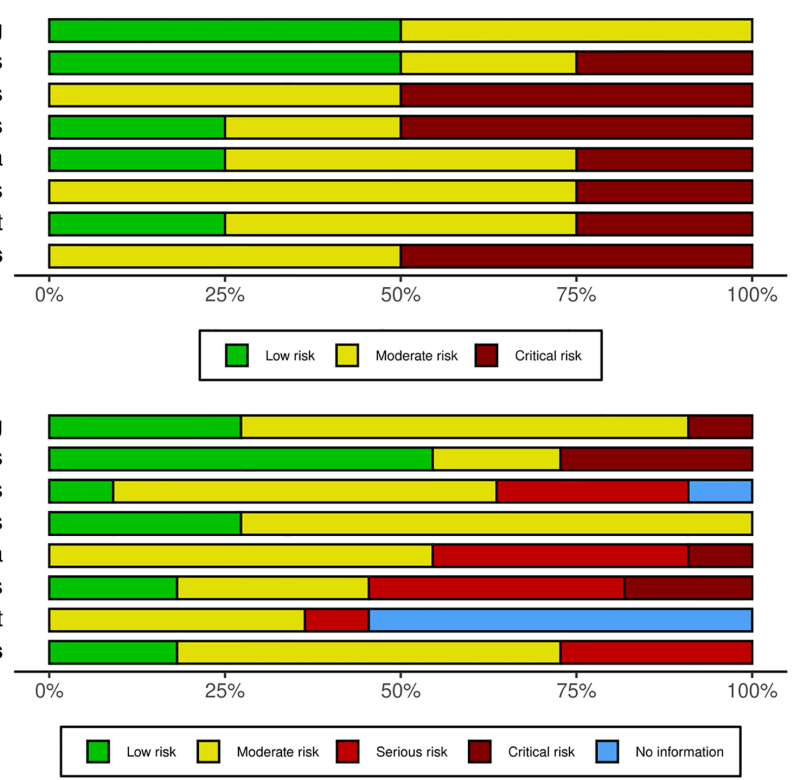

FIGURE 1 | Methodological quality graph for meta-analysis of the incidence (A), outcomes of surgery (B) and prognosis (C) of bladder cancer. The review authors' judgements about each methodological quality item of ROBINS-I presented as different colors across all included studies. The red, yellow and green colors represent critical, moderate and low bias, respectively. 


\section{RESULTS}

\section{Retrospective Study to Explore the Association of Aspirin Intake and Risk of Bladder Cancer \\ Baseline Characteristics}

The clinical characteristics of the 1121 cases and 2242 controls are shown in Table 2. The following variable information was selected as the prognostic factors in our study: age at diagnosis $<68$ or $>68$, marital status, smoking status (nonsmoker, current smoker, former smoker), alcohol use (nondrinker, current drinker, former drinker), history of aspirin intake (yes, no), history of metformin use (yes, no), history of cardiovascular disease (yes, no), history of cerebrovascular disease (yes, no), and history of diabetes (yes, no). In the multivariate logistic regression analysis, we found that gender $(\mathrm{OR}=1.263 ; 95 \%$ $\mathrm{CI}=1.026-1.556 ; P=0.028) ;$ marital status $(\mathrm{OR}=0.165 ; 95 \%$ $\mathrm{CI}=0.940-0.289 ; P<0.001)$; current smoking status $(\mathrm{OR}=$ $2.360 ; 95 \% \mathrm{CI}=1.936-2.875 ; P<0.001)$; current alcohol use $(\mathrm{OR}=0.615 ; 95 \% \mathrm{CI}=0.496-0.762 ; P<0.001)$; former alcohol use $(\mathrm{OR}=0.314 ; 95 \% \mathrm{CI}=0.188-0.525 ; P<0.001)$ and history of cardiovascular disease $(\mathrm{OR}=0.212 ; 95 \% \mathrm{CI}=0.162-0.276$; $P<0.001)$ were associated with a strong risk of $\mathrm{BCa}$.

\section{The Association of Aspirin Intake and Risk of Bladder Cancer}

Among the controls and the cases identified as $\mathrm{BCa}$, the patients who used aspirin accounted for $10.1 \%$ of the total number of patients with BCa and $11.6 \%$ of the control group. As shown in Table 3, The analysis showed that the regular use of aspirin was notassociated with a reduced incidence of $\mathrm{BCa}(\mathrm{OR}=0.851,95 \% \mathrm{CI}=0.674-1.075, P=0.175)$. Subgroup analyses stratified by sex showed no correlation between aspirin intake and the risk of $\mathrm{BCa}$ in female patients $(\mathrm{OR}=2.000,95 \%$ $\mathrm{CI}=0.950-4.190, P=0.063$ ). However, the male population who regularly took aspirin had a lower incidence of $\mathrm{BCa}(\mathrm{OR}=0.748,95 \%$ $\mathrm{CI}=0.584-0.958, P=0.021$ ). Moreover, subgroup analyses stratified by smoking status showed no reduction in the risk of $\mathrm{BCa}$ for nonsmokers $(\mathrm{OR}=1.200,95 \% \mathrm{CI}=0.879-1.630, P=0.252)$ or former smokers $(\mathrm{OR}=0.913,95 \% \mathrm{CI}=0.437-1.900, P=0.807)$ who used aspirin daily. In contrast, our results found a significant reduction in the risk of $\mathrm{BCa}$ in current smokers with aspirin intake $(\mathrm{OR}=0.522,95 \% \mathrm{CI}=0.342$ $0.797, P=0.002$ ). In addition, subgroup analyses stratified by drinking status showed no change in the risk of $\mathrm{BCa}$ for nondrinkers $(\mathrm{OR}=0.970,95 \% \mathrm{CI}=0.744-1.260, P=0.822)$, current drinkers $(\mathrm{OR}=0.651,95 \% \mathrm{CI}=0.377-1.120, P=0.121)$, or former drinkers $(\mathrm{OR}=0.227,95 \% \mathrm{CI}=0.029-1.780, P=0.126)$ who used aspirin daily.

TABLE 2 | Demographic characteristics of bladder cancer cases and controls.

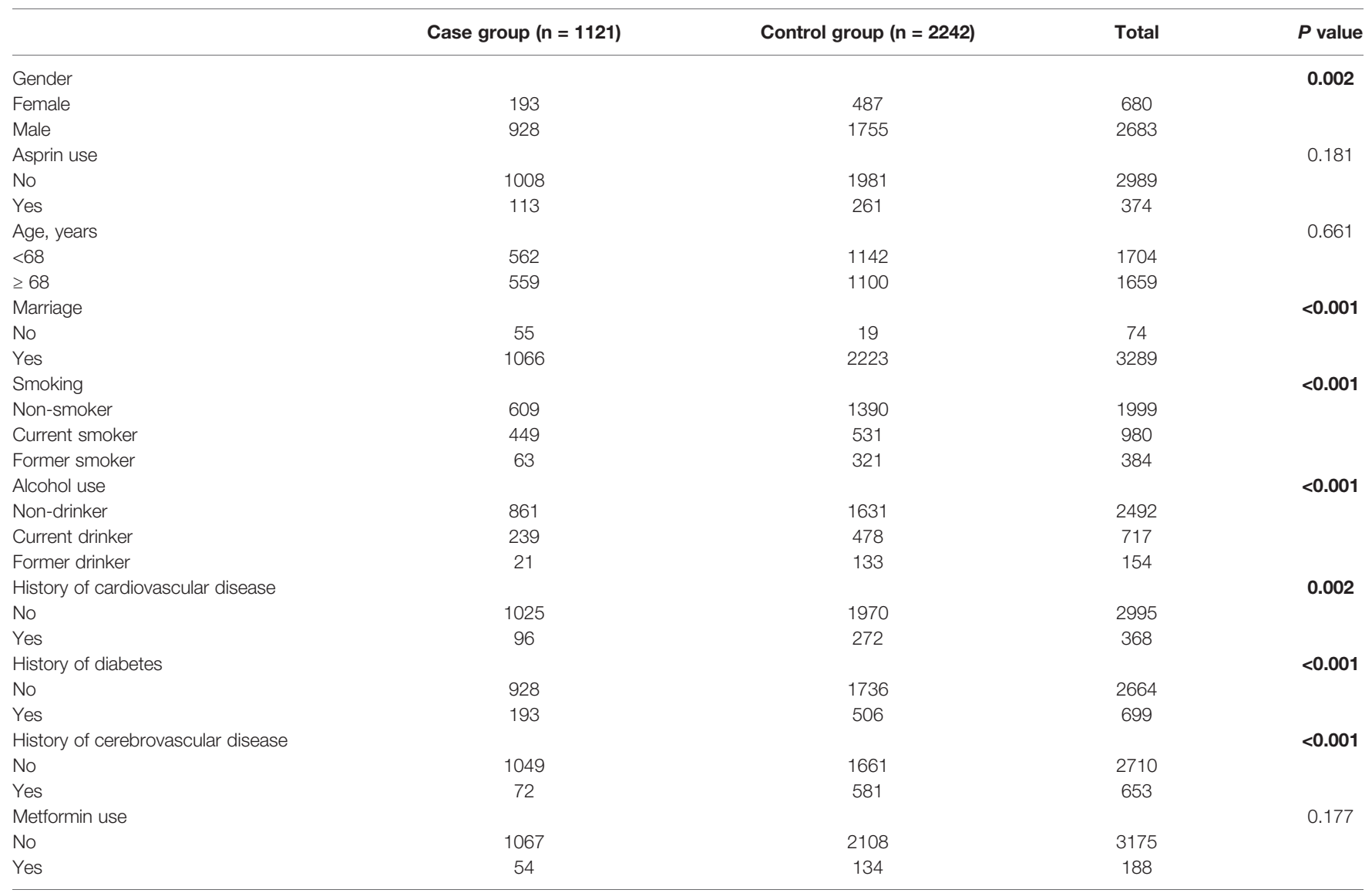

The bold values were applied to highlight $P$-values which had statistically significance (i.e. $P<0.05$ ). 
TABLE 3 | Univariate and multivariate logistic regression analysis of risk factors for bladder cancer.

\begin{tabular}{|c|c|c|c|c|}
\hline & \multicolumn{2}{|c|}{ Univariate analysis } & \multicolumn{2}{|c|}{ Multivariate analysis } \\
\hline & HR $(95 \% \mathrm{Cl})$ & $p$ value & HR $(95 \% \mathrm{Cl})$ & $P$ value \\
\hline Sex Female vs. Male & $1.334(1.109-1.605)$ & 0.002 & $1.263(1.026-1.556)$ & 0.028 \\
\hline Aspirin use Yes vs. no & $0.851(0.674-1.075)$ & 0.175 & & \\
\hline Age <68 vs. $>68$ & 1.033 (0.895-1.192) & 0.661 & & \\
\hline Marital Status Yes vs. Others & $0.166(0.098-0.280)$ & $<0.001$ & $0.165(0.94-0.289)$ & $<0.001$ \\
\hline \multicolumn{5}{|l|}{ Smoking } \\
\hline \multicolumn{5}{|l|}{ Non-smoker } \\
\hline Current smoker & $1.930(1.648-2.260)$ & $<0.001$ & $2.360(1.936-2.875)$ & $<0.001$ \\
\hline Former smoker & $0.448(0.336-0.596)$ & $<0.001$ & $0.744(0.537-1.031)$ & 0.076 \\
\hline \multicolumn{5}{|l|}{ Alcohol use } \\
\hline \multicolumn{5}{|l|}{ Non-drinker } \\
\hline Current drinker & 0.947 (0.794-1.129) & 0.545 & $0.615(0.496-0.762)$ & $<0.001$ \\
\hline Former drinker & $0.299(0.187-0.477)$ & $<0.001$ & $0.314(0.188-0.525)$ & $<0.001$ \\
\hline History of cerebrovascular disease yes vs. others & $0.678(0.531-0.866)$ & 0.002 & $0.863(0.662-1.126)$ & 0.279 \\
\hline diabetes yes vs. others & $0.714(0.594-0.858)$ & $<0.001$ & $0.845(0.694-1.028)$ & 0.093 \\
\hline History of cardiovascular disease yes vs. others & $0.196(0.152-0.254)$ & $<0.001$ & $0.212(0.162-0.276)$ & $<0.001$ \\
\hline Metformin use yes vs. others & $0.796(0.576-1.101)$ & 0.168 & & \\
\hline
\end{tabular}

The bold values were applied to highlight $P$-values which had statistically significance (i.e. $P<0.05)$.

\section{Retrospective Study to Explore the Association of Aspirin Intake and Prognosis of Bladder Cancer Aspirin Intake and Clinicopathological Characteristics of Bladder Cancer}

A total of 1121 patients with newly developed BCa from Northeast China, mainland China, were identified from 2002 to January 2019 and divided into aspirin and non-aspirin groups.
Of these patients in Table 4, the male to female ratio was 928:193, and there were 559 patients aged 68 or greater. A total of 344 patients $(30.7 \%)$ had pathologic stage $\mathrm{T}_{2}-\mathrm{T}_{4}$ disease, and 687 patients (61.3\%) had high-grade disease (G2 to G3). Positive lymph nodes were present in 62 patients (5.3\%), and distant metastasis was present in 33 patients (2.9\%). All patients had a definite type of surgery; 854 underwent TURBT (76.2\%), 58 underwent partial resection (5.2\%), and 209

TABLE 4 | Association between aspirin intake and clinico-pathological characteristics of 1121 BCa patients.

\begin{tabular}{|c|c|c|c|c|}
\hline & \multicolumn{2}{|c|}{ Regular Aspirin use } & Total & $P$ value \\
\hline Gender & & & & 0.090 \\
\hline Male & 828 & 100 & 928 & \\
\hline Female & 180 & 13 & 193 & \\
\hline Age, years & & & & $<0.001$ \\
\hline Less than 68 & 529 & 33 & 562 & \\
\hline $\mathrm{T}_{\text {is }}-\mathrm{T}_{1}$ & 702 & 75 & 777 & \\
\hline $\mathrm{T}_{2}-\mathrm{T}_{4}$ & 306 & 38 & 344 & \\
\hline Pathologic grade & & & & 0.852 \\
\hline $\mathrm{G}_{1}$ & 393 & 41 & 434 & \\
\hline $\mathrm{G}_{2}$ & 165 & 19 & 184 & \\
\hline $\mathrm{G}_{3}$ & 450 & 53 & 503 & \\
\hline $\mathrm{N}_{3}$ & 2 & 0 & 2 & \\
\hline Distant metastasis & & & & 0.693 \\
\hline $\mathrm{M}_{0}$ & 979 & 109 & 1088 & \\
\hline$M_{1}$ & 29 & 4 & 33 & \\
\hline Type of surgery & & & & 0.172 \\
\hline TURBT & 773 & 81 & 854 & \\
\hline PC & 54 & 4 & 58 & \\
\hline $\mathrm{RC}$ & 181 & 28 & 209 & \\
\hline
\end{tabular}

TURBT, Transurethral resection of bladder tumor; PC, Partial cystectomy; RC, Radical cystectomy.

The bold values were applied to highlight $P$-values which had statistically significance (i.e. $P<0.05$ ). 
underwent radical prostatectomy (18.6\%). The characteristics of bladder cancer patients, such as sex $(P=0.090)$ and type of surgery $(P=0.172)$, were not correlated with a history of aspirin intake. Similarly, tumor characteristics such as pT stage $(P=0.475)$, pathologic grade $(P=0.852)$, lymph node status $(P=0.866)$, and distant metastasis $(P=0.693)$ were also not correlated with a history of aspirin intake. However, age $(P<0.001)$ was associated with a history of aspirin intake.

\section{The Association of Aspirin Intake and the Prognosis in Patients With BCa}

Of the 1121 patients, the median follow-up among survivors was 50.1 months. Seventy-nine patients (7.0\%) died, and 235 patients (21.0\%) experienced relapse. By KM plotter drawing, we did not find that patients with a history of aspirin intake had a markedly longer OS or RFS than those with no history of aspirin intake. To explore prognostic factors for bladder cancer, patient-specific and tumor-specific features, together with a history of aspirin intake, were incorporated into the Cox regression model. Notably, distant metastasis $(\mathrm{HR}=2.611 ; 95 \% \mathrm{CI}=1.170-5.826$, $P=0.019)$ and type of surgery $(\mathrm{HR}=1.398 ; 95 \% \mathrm{CI}=1.066-1.833$, $P=0.015)$ were significantly associated with OS (Table 5). Moreover, pT stage $(\mathrm{HR}=1.728$; 95\% $\mathrm{CI}=1.324-2.254, P<0.001)$ was an independent predictor for RFS after multivariate analysis. However, a history of aspirin intake was not an independent factor for OS or RFS (Table 6). Stratified analysis by sex showed no correlation between aspirin intake and the recurrence of $\mathrm{BCa}$ for either male patients $(P=0.325)$ or female patients $(P=0.617)$.
Furthermore, aspirin intake was not significantly associated with overall survival in male $(P=0.071)$ or female patients $(P=0.646)$ with BCa. Stratified analysis by sex showed no correlation between aspirin intake and the recurrence of $\mathrm{BCa}$ for either male patients $(P=0.325)$ or female patients $(P=0.617)$. Stratified analysis by age showed no change between aspirin intake and the recurrence of $\mathrm{BCa}$ for both patients younger than 68 years old $(P=0.489)$ and patients older than 68 years $(P=0.916)$. Furthermore, aspirin intake was not significantly associated with overall survival in patients older than 68 years $(P=0.318)$. Interestingly, aspirin intake $(\mathrm{HR}=3.876 ; 95 \% \mathrm{CI}=1.326-11.325$, $P=0.019)$ and type of surgery $(\mathrm{HR}=1.685 ; 95 \% \mathrm{CI}=1.131-1.131$, $P=0.010$ ) were significantly associated with $\mathrm{OS}$ in BCa patients younger than 68 years old after Cox multivariate regression analysis.

\section{Meta-Analysis}

\section{Study Identification and Selection}

The selection process following the Preferred Reporting Items for Systematic Review and Meta-Analysis (PRISMA) reporting guideline for the association of aspirin intake with the risk and prognosis of $\mathrm{BCa}$ is presented in Figure 2. Initially, the database search retrieved 1107 relevant publications. After screening the titles, abstracts and full texts of these articles, we excluded duplicate studies and other studies for various reasons (reviews/editorials, animal/molecular biology studies, or not relevant to our analysis etc.). Thus, in the final analysis, we included 19 studies about the relation of aspirin intake risk of

TABLE 5 | Univariate and multivariate Cox regression model for overall survival (OS) including known parameters in 1121 BCa patients treated with surgery.

\begin{tabular}{|c|c|c|c|c|}
\hline \multirow[t]{2}{*}{ Overall Survival } & \multicolumn{2}{|c|}{ Univariate analysis } & \multicolumn{2}{|c|}{ Multivariate analysis } \\
\hline & $\mathrm{HR}(95 \% \mathrm{Cl})$ & $P$ value & $\mathrm{HR}(95 \% \mathrm{Cl})$ & $P$ value \\
\hline Gender & $2.344(1.018-5.397)$ & 0.045 & 2.137 (0.924-4.944) & 0.076 \\
\hline Age & $1.697(1.077-2.675)$ & 0.023 & 1.392 (0.869-2.229) & 0.169 \\
\hline pT stage & $1.810(1.157-2.832)$ & 0.009 & $1.218(0.728-2.037)$ & 0.453 \\
\hline Pathologic grade & $1.201(0.939-1.535)$ & 0.145 & & \\
\hline Lymph node status & $0.662(0.273-1.606)$ & 0.362 & & \\
\hline Distant metastasis & $3.552(1.626-7.760)$ & 0.001 & $2.611(1.170-5.826)$ & 0.019 \\
\hline Type of surgery & 1.598 (1.263-2.023) & $<0.001$ & 1.398 (1.066-1.833) & 0.015 \\
\hline Aspirin use & $2.045(1.100-3.802)$ & 0.024 & $1.653(0.871-3.137)$ & 0.124 \\
\hline
\end{tabular}

The bold values were applied to highlight $P$-values which had statistically significance (i.e. $P<0.05)$.

TABLE 6 | Univariate and multivariate Cox regression model for recurrence-free survival (RFS) including known parameters in 1121 BCa patients treated with surgery.

\begin{tabular}{|c|c|c|c|c|}
\hline \multirow[t]{2}{*}{ Overall Survival } & \multicolumn{2}{|c|}{ Univariate analysis } & \multicolumn{2}{|c|}{ Multivariate analysis } \\
\hline & HR $(95 \% \mathrm{Cl})$ & $P$ value & HR $(95 \% \mathrm{Cl})$ & $\boldsymbol{P}$ value \\
\hline Gender & $1.070(0.753-1.521)$ & 0.706 & & \\
\hline Age & $1.284(0.992-1.663)$ & 0.058 & & \\
\hline pT stage & $1.812(1.396-2.351)$ & $<0.001$ & $1.728(1.324-2.254)$ & $<0.001$ \\
\hline Pathologic grade & $1.173(1.016-1.353)$ & 0.029 & 1.103 (0.954-1.227) & 0.186 \\
\hline Lymph node status & $1.321(0.960-1.819)$ & 0.087 & & \\
\hline Distant metastasis & $1.936(1.055-3.551)$ & 0.033 & 1.702 (0.925-3.132) & 0.087 \\
\hline Type of surgery & $1.133(0.971-1.321)$ & 0.112 & & \\
\hline Aspirin use & $1.170(0.772-1.774)$ & 0.459 & & \\
\hline
\end{tabular}

The bold values were applied to highlight $P$-values which had statistically significance (i.e. $P<0.05$ ). 


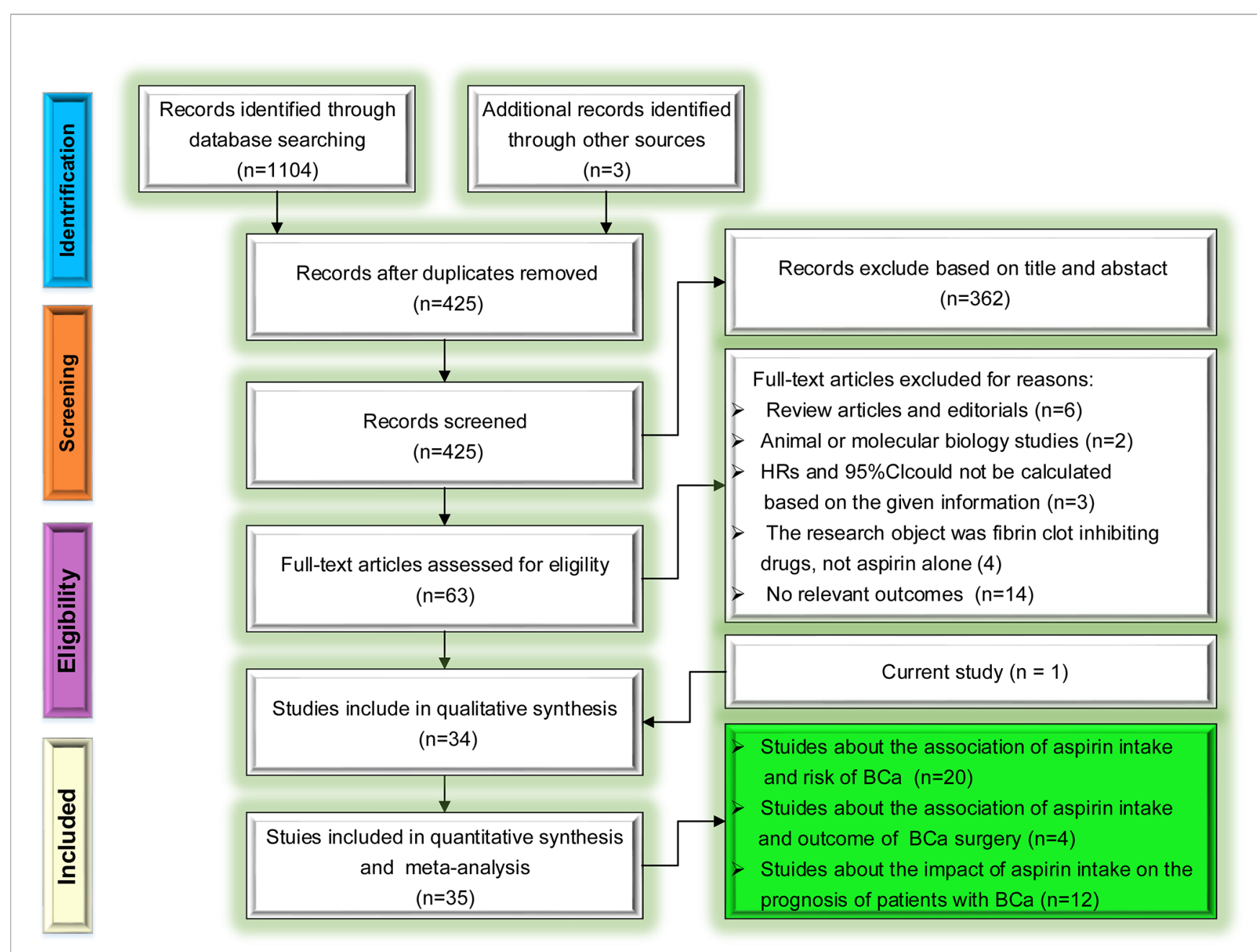

FIGURE 2 | Preferred Reporting Items for Systematic Review and Meta-Analysis (PRISMA) flow diagram for the selection of articles.

BCa, 4 studies about outcome of BCa surgery and 11 studies about the relation of aspirin intake and prognosis of patients with $\mathrm{BCa}$ based on the inclusion criteria.

\section{Characteristics of the Studies}

The characteristics of the 19 included trials (29-47) about the relation of aspirin intake and risk of $\mathrm{BCa}$ were provided in Table 7. These trials were published between 1989 and 2021. Of the 20 included articles which include our studies, finally contains 31 studies. In these studies, nine were conducted in the North America (29-31, 33-36, 44, 45), four in Asia (38, 41, 42), four in Europe $(32,37,46,47)$, and three in multi-regions $(39,40$, 43). Among all studies enrolled, eleven were cohort studies (29, $30,34,38-42,44-46)$, and eight were case-control studies (31-33, $35-37,47)$ containing this study. The given sample size of the trials ranged from 839 to 612509 , with a total of more than 39524 patients with $\mathrm{BCa}$. The characteristics of the four included trials (48-51) involving the relationship of aspirin intake and clinical course of bladder tumor surgery were provided in Table 8. These researches were published from 2013 to 2019 and from the USA (50), Italy (51), France (49) and Germany (48), respectively. The characteristics of the eleven included trials regarding the impact of aspirin intake on the prognosis of patients with $\mathrm{BCa}$ were presented in Table 9. The selected studies were published between 2004 and 2021. Combined with our study, eight studies originated from the USA $(52,53,55-60)$, one was from Italy (61), one was from India (54) and one was from multiregions (39). The sample size of the trials ranged from 43 to 139896. Among the twelve studies enrolled, eleven were cohort studies $(39,52-61)$, and only one was case-control study.

\section{The Association Between Aspirin Intake and the Risk of Bladder Cancer}

Overall Analysis

31 studies reported the effect estimates of the association between aspirin intake and the occurrence of BCa. The fixed-effects model was applied because the test for heterogeneity was not significant $\left(\mathrm{I}^{2}=0.00 \%, P=0.586\right)$. We found that patients with aspirin intake did not have a significantly lower risk of $\mathrm{BCa}$ than those without aspirin intake $(\mathrm{RR}=1.007,95 \% \mathrm{CI}=0.975-1.041, P=0.671)$. The sensitivity analysis demonstrated that no single trial had significantly influenced the pooled RR (Figure 3). This result 
TABLE 7 | Main characteristics of individual studies included in the meta-analysis on impact of aspirin intake on risk of BCa.

\begin{tabular}{|c|c|c|c|c|c|c|c|c|c|}
\hline $\begin{array}{l}\text { First author } \\
\text { (year) }\end{array}$ & Region & Study type & $\begin{array}{l}\text { Study } \\
\text { period }\end{array}$ & Age & $\begin{array}{c}\text { Total } \\
\text { number }\end{array}$ & $\begin{array}{c}\text { BCa } \\
\text { Cases }\end{array}$ & Dose of use & $\begin{array}{l}\text { Frequency/duration } \\
\text { of use }\end{array}$ & Adjusted HR/RR/OR (95\% Cl) \\
\hline Loomans-Kropp & Multi- & Cohort study; & 1993- & $55-$ & 139896 & 1751 & NA & $\geq 3$ times/week & $0.99(0.90-1.10)$ \\
\hline HA (39) & regions & Prospective & 2001 & 74 & & & & $<3$ times/week & $0.96(0.87-1.06)$ \\
\hline Orchard SG (40) & $\begin{array}{l}\text { Multi- } \\
\text { regions }\end{array}$ & $\begin{array}{l}\text { Cohort study; } \\
\text { Prospective }\end{array}$ & $\begin{array}{l}2010- \\
2014\end{array}$ & $\begin{array}{c}\geq \\
65\end{array}$ & 19030 & 142 & 100mg/day & NA & $1.02(0.59-1.77)$ \\
\hline Sung JJ (41) & China & $\begin{array}{l}\text { Cohort study; } \\
\text { Retrospective }\end{array}$ & $\begin{array}{l}2000- \\
2013\end{array}$ & $>18$ & 138966 & 2962 & z80mg/day & $\geq 6$ months & $0.93(0.83-1.05)$ \\
\hline Tsoi K (38) & China & $\begin{array}{l}\text { Cohort study; } \\
\text { Retrospective }\end{array}$ & $\begin{array}{c}2000- \\
2004\end{array}$ & 67.5 & 612509 & 5291 & 80mg/day & $\geq 6$ months & $1.06(0.98-1.14)$ \\
\hline Guercio V (37) & Italy & $\begin{array}{l}\text { Case control; } \\
\text { Retrospective }\end{array}$ & $\begin{array}{c}2003- \\
2014\end{array}$ & 67 & 1355 & 690 & NA & $\begin{array}{l}\geq 1 \text { times/week for } \geq 6 \\
\text { months }\end{array}$ & $1.21(0.87-1.68)$ \\
\hline Kang M (42) & Korea & $\begin{array}{l}\text { Cohort Study; } \\
\text { Prospective }\end{array}$ & $\begin{array}{l}2002- \\
2013\end{array}$ & $>40$ & 320613 & 2121 & NA & NA & $1.05(0.87-1.27)$ \\
\hline Stegeman I (43) & $\begin{array}{l}\text { Multi- } \\
\text { regions }\end{array}$ & Others & $\begin{array}{c}2006- \\
2015\end{array}$ & $\begin{array}{c}40- \\
85\end{array}$ & NA & NA & NA & NA & $0.94(0.64-1.38)$ \\
\hline Brasky TM (44) & USA & $\begin{array}{l}\text { Cohort study; } \\
\text { Prospective }\end{array}$ & $\begin{array}{l}1993- \\
2010\end{array}$ & $\begin{array}{c}50- \\
79\end{array}$ & 126689 & 154 & $\leq 100 \mathrm{mg} /$ day & $\begin{array}{l}\geq 2 \text { times/week for } \geq 2 \\
\text { weeks }\end{array}$ & $1.12(0.63-1.98)$ \\
\hline Shih C (36) & USA & $\begin{array}{l}\text { Case control; } \\
\text { Retrospective }\end{array}$ & $\begin{array}{l}2000- \\
2010\end{array}$ & $\begin{array}{l}50- \\
76\end{array}$ & 77048 & 385 & $\begin{array}{l}\text { Regular } \\
\text { Aspirin NA }\end{array}$ & $\begin{array}{l}1-3 \text { days/week for } \\
<4 \text { years } \\
4 \text { days/week for } \geq 4 \\
\text { years } \\
1-3 \text { days/week for } \\
<4 \text { years } \\
4 \text { days/week for } \geq 4 \\
\text { years }\end{array}$ & $\begin{array}{l}1.00(0.73-1.38) \\
1.00(0.73-1.38) \\
1.03(0.77-1.38)\end{array}$ \\
\hline Daugherty SE (35) & USA & $\begin{array}{l}\text { Case control; } \\
\text { Retrospective }\end{array}$ & $\begin{array}{l}1993- \\
2001\end{array}$ & 63.5 & 508842 & 2489 & NA & $\begin{array}{l}<2 \text { times/week } \\
>2 \text { times/week }\end{array}$ & $\begin{array}{l}1.03(0.92-1.15) \\
1.04(0.94-1.15)\end{array}$ \\
\hline Genkinger JM (34) & USA & $\begin{array}{l}\text { Cohort study; } \\
\text { Retrospective }\end{array}$ & $\begin{array}{l}1986- \\
2002\end{array}$ & $\begin{array}{c}40- \\
75\end{array}$ & 49448 & 607 & NA & $\geq 2$ times/week & $0.99(0.83-1.18)$ \\
\hline Fortuny J (33) & USA & $\begin{array}{l}\text { Case control; } \\
\text { Retrospective }\end{array}$ & $\begin{array}{l}1997- \\
2000\end{array}$ & $\begin{array}{l}25- \\
74\end{array}$ & 839 & 376 & NA & $\begin{array}{l}\geq 4 \text { times/week for } \\
\geq 1 \text { month }\end{array}$ & $0.60(0.40-0.90)$ \\
\hline Jacobs EJ (45) & USA & $\begin{array}{l}\text { Cohort Study; } \\
\text { Prospective }\end{array}$ & $\begin{array}{l}1992- \\
2003\end{array}$ & $\geq 50$ & 146113 & 18127 & $\geq 325 \mathrm{mg} /$ day & $\begin{array}{l}\text { Nonregular use } \\
<5 \text { years: } \\
>5 \text { years: }\end{array}$ & $\begin{array}{l}1.03(0.86-1.24) \\
0.97(0.76-1.22) \\
0.83(0.58-1.19)\end{array}$ \\
\hline Fortuny J (32) & Spain & $\begin{array}{l}\text { Case control; } \\
\text { Retrospective }\end{array}$ & $\begin{array}{l}1997- \\
2000\end{array}$ & $\begin{array}{l}20- \\
80\end{array}$ & 1987 & 958 & NA & $\begin{array}{l}\text { Nonregular use } \\
\geq 2 \text { times/week for } \\
\geq 1 \text { month }\end{array}$ & $\begin{array}{l}1.00(0.80-1.20) \\
1.00(0.70-1.50)\end{array}$ \\
\hline Friis S (46) & Denmark & $\begin{array}{l}\text { Cohort study; } \\
\text { Prospective }\end{array}$ & $\begin{array}{l}1989- \\
1997\end{array}$ & 70 & 29470 & 134 & $\begin{array}{l}75-150 \text { mg/ } \\
\text { day }\end{array}$ & $\begin{array}{l}1 \text { time/day for } 3 \\
\text { months }\end{array}$ & $1.20(1.00-1.40)$ \\
\hline Castelao JE (31) & USA & $\begin{array}{l}\text { Case control; } \\
\text { Retrospective }\end{array}$ & $\begin{array}{l}1987- \\
1996\end{array}$ & 58 & 3028 & 1514 & NA & $\begin{array}{l}\geq 2 \text { times/week for } \geq \\
1 \text { month }\end{array}$ & $0.85(0.66-1.09)$ \\
\hline Pommor W (47) & Germany & $\begin{array}{l}\text { Case control; } \\
\text { Retrospective }\end{array}$ & $\begin{array}{l}1990- \\
1995\end{array}$ & NA & 2180 & 571 & NA & NA & $1.09(0.73-1.64)$ \\
\hline $\begin{array}{l}\text { Schreinemachers } \\
\text { DM (30) }\end{array}$ & USA & $\begin{array}{l}\text { Cohort study; } \\
\text { Prospective }\end{array}$ & $\begin{array}{l}1982- \\
1987\end{array}$ & $\begin{array}{l}25- \\
74\end{array}$ & 12668 & 35 & NA & $\geq 1$ time/month & $1.06(0.54-2.09)$ \\
\hline $\begin{array}{l}\text { Paganini-Hill A } \\
\text { (29) }\end{array}$ & USA & $\begin{array}{l}\text { Cohort study; } \\
\text { Prospective }\end{array}$ & $\begin{array}{l}1981- \\
1988\end{array}$ & 73 & 13987 & 96 & NA & $\begin{array}{l}<1 \text { time/day } \\
\geq 1 \text { time/day }\end{array}$ & $\begin{array}{c}\text { Male: } 0.37(0.13-1.02) \text { Female: } \\
1.52(0.55-4.23) \\
\text { Male: } 1.12(0.63-1.99) \text { Female: } \\
\\
0.89(0.26-3.10)\end{array}$ \\
\hline This study & China & $\begin{array}{l}\text { Case control; } \\
\text { Retrospective }\end{array}$ & $\begin{array}{l}2002- \\
2019\end{array}$ & 68 & 3363 & 1121 & z80mg/day & $\geq 1$ months & $0.85(0.67-1.08)$ \\
\hline
\end{tabular}

exhibited a low probability of publication bias, as determined by Begg's test $(\mathrm{P}=1.000)$ and Egger's test $(P=0.709$, Figure 3B $)$. However, low dose $(<100 \mathrm{mg} /$ day $)$ aspirin intake impacted on risk of $\mathrm{BCa}(\mathrm{RR}=1.072,95 \% \mathrm{CI}=1.004-1.145, P=0.038)$.

\section{Sensitivity Analysis}

The effects for heterogeneity of each study were evaluated by leave-one-out sensitivity analysis. As shown in Figure $\mathbf{4 A}$, the forest plots were equally applied, indicating that the identified studies in our meta-analysis had no significant influence to heterogeneity. Additionally, the respective values of $I^{2}$ and $P_{\mathrm{Q}}$ were enriched in Figure 4B. There were low heterogeneity after leaving the individual single study out, suggesting that the metaanalysis based on the pooled studies was credible.

\section{Subgroup Analysis by Whether Regular \\ Use of Aspirin}

Fixed-effects model was applied on account of little heterogeneity $\left(\mathrm{I}^{2}=0.8 \%, P=0.451\right)$. There were no dependency between aspirin use and $\mathrm{BCa}$ in the group of regular users $(\mathrm{RR}=1.012$, 
TABLE 8 | Main characteristics of eligible studies collected in the meta-analysis on effect of aspirin intake on outcome of surgery for BCa.

\begin{tabular}{|c|c|c|c|c|c|c|c|c|c|}
\hline $\begin{array}{l}\text { First author } \\
\text { (year) }\end{array}$ & Region & Study type & $\begin{array}{l}\text { Study } \\
\text { period }\end{array}$ & Age & $\begin{array}{c}\mathrm{BCa} \\
\text { Cases }\end{array}$ & $\begin{array}{l}\text { Surgical } \\
\text { approach }\end{array}$ & $\begin{array}{l}\text { Dose of } \\
\text { use }\end{array}$ & $\begin{array}{l}\text { Frequency/ } \\
\text { Duration of use }\end{array}$ & Adjusted HR/RR/OR (95\% Cl) \\
\hline Wessels F (48) & Germany & $\begin{array}{l}\text { Retrospective cohort } \\
\text { study }\end{array}$ & $\begin{array}{l}2011- \\
2017\end{array}$ & 65 & 461 & $\mathrm{RC}$ & NA & NA & $\begin{array}{c}\text { BTR:1.12(0.80-1.57) IACR:1.48 } \\
(0.77-2.86)\end{array}$ \\
\hline Prader R (49) & France & $\begin{array}{l}\text { Retrospective case- } \\
\text { control study }\end{array}$ & $\begin{array}{l}2013- \\
2015\end{array}$ & $\begin{array}{l}53- \\
83\end{array}$ & 234 & TURBT & $\begin{array}{l}\geq 75 \mathrm{mg} / \\
\text { day }\end{array}$ & NA & $\begin{array}{l}\text { BTR:1.38 (0.09-21.70) } \\
\text { IACR:1.15 (0.36-3.64) } \\
\text { IHO:4.12 (0.17-99.83) }\end{array}$ \\
\hline Ghali F (50) & USA & $\begin{array}{l}\text { Retrospective case- } \\
\text { control study }\end{array}$ & $\begin{array}{l}2011- \\
2014\end{array}$ & 70 & 708 & TURBT & NA & NA & IACR:0.38 (0.15-0.92) \\
\hline Picozzi S (51) & Italy & Cohort study & $\begin{array}{l}2007- \\
2012\end{array}$ & $\begin{array}{l}74- \\
68\end{array}$ & 158 & TURBT & $\begin{array}{l}\text { 100mg/ } \\
\text { day }\end{array}$ & NA & $\begin{array}{l}\text { BTR:1.94 (0.36-10.39) } \\
\text { IHO:1.46 (0.25-8.55) }\end{array}$ \\
\hline
\end{tabular}

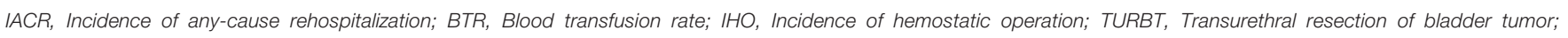
$R C$, Radical cystectomy.

TABLE 9 | Main characteristics of eligible studies collected in the meta-analysis on effect of aspirin intake on prognosis of BCa.

\begin{tabular}{|c|c|c|c|c|c|c|c|c|c|}
\hline $\begin{array}{l}\text { First author } \\
\text { (year) }\end{array}$ & Region & Study type & $\begin{array}{l}\text { Study } \\
\text { period }\end{array}$ & Age & $\begin{array}{c}\text { Total } \\
\text { number }\end{array}$ & $\begin{array}{c}\mathrm{BCa} \\
\text { cases }\end{array}$ & Dose of use & $\begin{array}{l}\text { Frequency/ } \\
\text { Duration of use }\end{array}$ & $\begin{array}{l}\text { Reported end- } \\
\text { points }\end{array}$ \\
\hline $\begin{array}{l}\text { Loomans- } \\
\text { Kropp HA (39) }\end{array}$ & $\begin{array}{l}\text { Multi- } \\
\text { regions }\end{array}$ & $\begin{array}{l}\text { Cohort study; } \\
\text { Prospective }\end{array}$ & $\begin{array}{l}1993- \\
2001\end{array}$ & 65 & 139896 & 1751 & NA & $\begin{array}{l}\geq 3 \text { times/week } \\
<3 \text { times/week }\end{array}$ & $\begin{array}{c}\text { CSS: } 0.67 \\
(0.51-0.88) \\
\text { CSS:0.75 } \\
(0.58-0.98)\end{array}$ \\
\hline Li P (52) & USA & $\begin{array}{l}\text { Cohort study; } \\
\text { Retrospective }\end{array}$ & 2016 & 65 & 63308 & 2600 & NA & NA & $\begin{array}{c}\text { OS: } 1.01 \\
(1.00-1.03)\end{array}$ \\
\hline Lyon TD (53) & USA & $\begin{array}{l}\text { Cohort study; } \\
\text { Retrospective }\end{array}$ & $\begin{array}{l}2007- \\
2016\end{array}$ & NA & 1061 & 1061 & $\begin{array}{l}25 \mathrm{mg} / \text { day } 81 \mathrm{mg} / \text { day } 162 \mathrm{mg} / \text { day } \\
325 \mathrm{mg} / \text { day } 650 \mathrm{mg} / \text { day }\end{array}$ & 3 months & $\begin{array}{c}\text { CSS: } 0.64 \\
(0.45-0.89) \\
\text { OS: } 0.70 \\
(0.53-0.93) \\
\text { MFS: } 0.96 \\
(0.68-1.36)\end{array}$ \\
\hline Gupta R (54) & India & $\begin{array}{l}\text { Cohort study; } \\
\text { Prospective }\end{array}$ & $\begin{array}{l}2015- \\
2017\end{array}$ & 58 & 103 & 103 & $75 \mathrm{mg} /$ day & $\geq 3$ months & $\begin{array}{c}\text { RFS: } 1.002 \\
(0.24-4.16) \\
\text { PFS:11.65 } \\
(0.11-1188.30)\end{array}$ \\
\hline Singla N (55) & USA & $\begin{array}{l}\text { Cohort study; } \\
\text { Prospective }\end{array}$ & $\begin{array}{l}2006- \\
2012\end{array}$ & 73 & 203 & 99 & $81 \mathrm{mg} /$ day $325 \mathrm{mg} /$ day & NA & $\begin{array}{c}\text { CSS: } 3.14 \\
(0.37-26.91) \\
\text { OS:1.91 } \\
(0.69-5.27) \\
\text { RFS:1.05 } \\
(0.64-1.74)\end{array}$ \\
\hline Pastore AL (56) & Italy & $\begin{array}{l}\text { Cohort study; } \\
\text { Retrospective }\end{array}$ & $\begin{array}{l}2008- \\
2013\end{array}$ & 62 & 574 & 574 & 100mg/day & $\geq 2$ years & $\begin{array}{l}\text { RFS: } 0.74 \\
(0.45-1.24)\end{array}$ \\
\hline Lipsky MJ (57) & USA & $\begin{array}{l}\text { Cohort study; } \\
\text { Retrospective }\end{array}$ & $\begin{array}{l}2001- \\
2011\end{array}$ & $\begin{array}{c}56- \\
82\end{array}$ & 224 & 224 & NA & NA & $\begin{array}{l}\text { RFS: } 2.41 \\
(1.08-5.35)\end{array}$ \\
\hline Jacobs EJ (58) & USA & $\begin{array}{l}\text { Cohort study; } \\
\text { Prospective }\end{array}$ & $\begin{array}{l}1997- \\
2008\end{array}$ & NA & 100139 & 302 & Baby low dose; Adult strength dose & $\geq 1$ months & $\begin{array}{c}\text { OS:0.75 } \\
(0.48-1.16)\end{array}$ \\
\hline Boorjian SA (59) & USA & $\begin{array}{l}\text { Cohort study; } \\
\text { Retrospective }\end{array}$ & $\begin{array}{l}1990- \\
2006\end{array}$ & $\begin{array}{l}57- \\
75\end{array}$ & 907 & 907 & NA & NA & $\begin{array}{l}\text { RFS: } 0.91 \\
(0.751 .10) \\
\text { PFS: } 0.71 \\
(0.52-0.96)\end{array}$ \\
\hline Gee JR (60) & USA & $\begin{array}{l}\text { Cohort study; } \\
\text { Retrospective }\end{array}$ & $\begin{array}{l}1991- \\
2003\end{array}$ & 67 & 43 & 43 & $81 \mathrm{mg} /$ day $325 \mathrm{mg} /$ day & NA & $\begin{array}{l}\text { RFS:0.18 } \\
(0.06-0.52) \\
\text { PFS: } 1.15 \\
(0.81-1.63)\end{array}$ \\
\hline $\begin{array}{l}\text { Ratnasinghe LD } \\
\text { (61) }\end{array}$ & USA & $\begin{array}{l}\text { Cohort study; } \\
\text { Prospective }\end{array}$ & $\begin{array}{l}1982- \\
1992\end{array}$ & $\begin{array}{c}25- \\
74\end{array}$ & 22794 & 40 & NA & NA & $\begin{array}{c}\text { OS: } 3.36 \\
(1.03-10.97)\end{array}$ \\
\hline This study & China & $\begin{array}{l}\text { Case control; } \\
\text { Retrospective }\end{array}$ & $\begin{array}{l}2002- \\
2019\end{array}$ & 68 & 1121 & 1121 & $\geq 80 \mathrm{mg} /$ day & $\geq 1$ months & $\begin{array}{c}\text { OS: } 1.653 \\
(0.871-3.137) \\
\text { RFS: } 1.17 \\
(0.772-1.774)\end{array}$ \\
\hline
\end{tabular}

OS, Overall survival; CSS, Cancer-specific survival; PFS, Progression-free survival; RFS, Recurrence-free survival; MFS, Metastasis-free survival. 

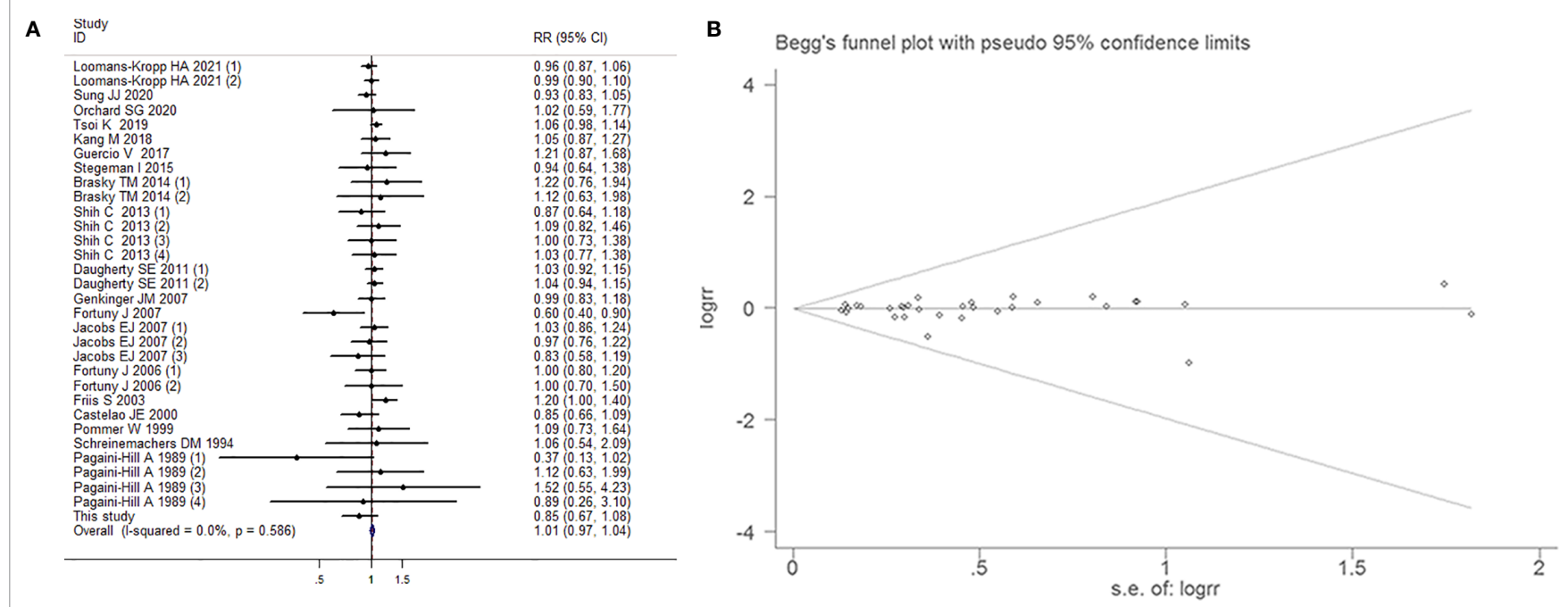

FIGURE 3 | Forest plot (A) and funnel plot (B) showing the relationship between aspirin intake and the risk of bladder cancer in the overall analysis. The Xcoordinate scale of solid lines perpendicular to the $\mathrm{X}$-axis is 1 . Each horizontal line segment parallel to the $\mathrm{X}$-axis represents a confidence interval of the research results. The wider the confidence interval is, the longer the horizontal line segment. The small square in the middle of the horizontal line represents the position of the point estimate of the OR, and the size represents the weight of the study, which represents the percentage of the results of each study in the overall results. The intersection of the horizontal segment and the solid vertical line indicates that the study results are not statistically significant. Diamonds represent the overall effect of the estimate using the Mantel-Haenszel fixed-effects model. The visual examination of the funnel plot showed no apparent asymmetry, indicating that the publication bias was small and that the effect on the combined effect was negligible.

95\% $\mathrm{CI}=0.974-1.053, P=0.535)$ and nonregular users $(\mathrm{RR}=1.026$, 95\% CI=0.943-1.116, $P=0.549)$, respectively. Begg's test $(P=0.802)$ and Egger's funnel plot asymmetry test $(P=0.624)$ manifested that there was no significant publication bias (Figure 5).

\section{Subgroup Analysis by the Mean Duration of Use of Aspirin}

Random effects model has been arranged because of strong heterogeneity $\left(\mathrm{I}^{2}=75.1 \%, P<0.001\right)$. The crowd with a mean

\section{'}

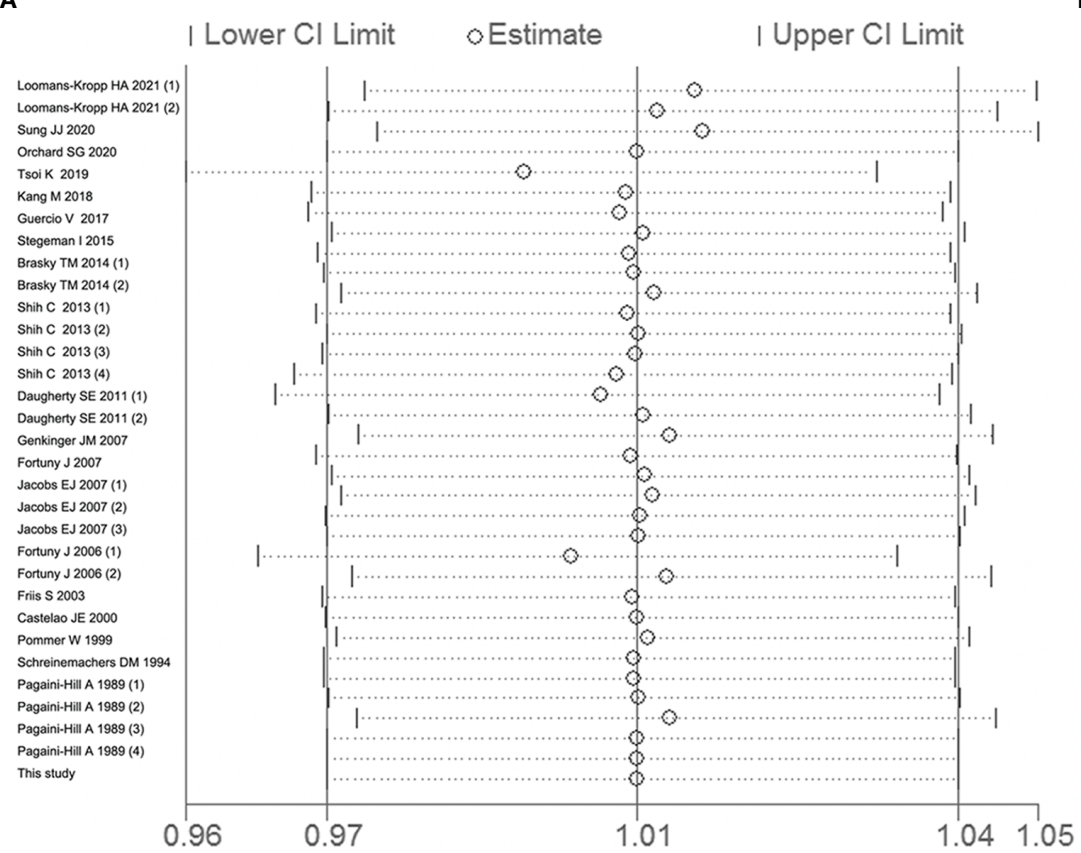

B

\begin{tabular}{|cccc}
\hline Study left out & Odds ratio(95\%Cl) & $\mathbf{I}^{2}$ & $\mathrm{PQ}_{\mathbf{Q}}$ \\
\hline Loomans-Kropp HA 2021 (1) & $1.013(0.979-1.049)$ & $0.0 \%$ & 0.588 \\
Loomans-Kropp HA 2021 (2) & $1.009(0.975-1.045)$ & $0.0 \%$ & 0.541 \\
\hline Sung JJ 2020 & $1.014(0.980-1.049)$ & $0.0 \%$ & 0.635 \\
Orchard SG 2020 & $1.007(0.975-1.041)$ & $0.0 \%$ & 0.534 \\
\hline Tsoi K 2019 & $0.995(0.960-1.032)$ & $0.0 \%$ & 0.648 \\
Kang M 2018 & $1.006(0.973-1.040)$ & $0.0 \%$ & 0.544 \\
Guercio V 2017 & $1.005(0.973-1.039)$ & $0.0 \%$ & 0.598 \\
Stegeman I 2015 & $1.008(0.975-1.041)$ & $0.0 \%$ & 0.541 \\
\hline Brasky TM 2014 (1) & $1.006(0.974-1.040)$ & $0.0 \%$ & 0.568 \\
Brasky TM 2014 (2) & $1.007(0.974-1.040)$ & $0.0 \%$ & 0.541 \\
\hline Shih C 2013 (1) & $1.009(0.976-1.043)$ & $0.0 \%$ & 0.581 \\
Shih C 2013 (2) & $1.006(0.974-1.040)$ & $0.0 \%$ & 0.550 \\
\hline Shih C 2013(3) & $1.007(0.975-1.041)$ & $0.0 \%$ & 0.534 \\
Shih C 2013 (4) & $1.007(0.974-1.041)$ & $0.0 \%$ & 0.535 \\
\hline Daugherty SE 2011 (1) & $1.005(0.971-1.040)$ & $0.0 \%$ & 0.543 \\
Daugherty SE 2011 (2) & $1.003(0.969-1.039)$ & $0.0 \%$ & 0.557 \\
\hline Genkinger JM 2007 & $1.008(0.975-1.042)$ & $0.0 \%$ & 0.536 \\
Fortuny J 2007 & $1.011(0.978-1.044)$ & $0.0 \%$ & 0.840 \\
Jacobs EJ 2007 (1) & $1.006(0.973-1.040)$ & $0.0 \%$ & 0.537 \\
Jacobs EJ 2007 (2) & $1.008(0.975-1.042)$ & $0.0 \%$ & 0.539 \\
\hline Jacobs EJ 2007 (3) & $1.009(0.976-1.042)$ & $0.0 \%$ & 0.594 \\
Fortuny J 2006 (1) & $1.007(0.974-1.041)$ & $0.0 \%$ & 0.534 \\
\hline Fortuny J 2006 (2) & $1.007(0.975-1.041)$ & $0.0 \%$ & 0.534 \\
Friis S 2003 & $1.000(0.967-1.034)$ & $0.0 \%$ & 0.756 \\
\hline Castelao JE 2000 & $1.010(0.977-1.044)$ & $0.0 \%$ & 0.629 \\
Pommer W 1999 & $1.007(0.974-1.040)$ & $0.0 \%$ & 0.542 \\
Schreinemachers DM 1994 & $1.007(0.975-1.041)$ & $0.0 \%$ & 0.535 \\
Pagaini-Hill A 1989 (1) & $1.008(0.976-1.042)$ & $0.0 \%$ & 0.723 \\
Pagaini-Hill A 1989 (2) & $1.007(0.974-1.040)$ & $0.0 \%$ & 0.541 \\
Pagaini-Hill A 1989 (3) & $1.007(0.974-1.040)$ & $0.0 \%$ & 0.567 \\
\hline Pagaini-Hill A 1989 (4) & $1.007(0.975-1.041)$ & $0.0 \%$ & 0.536 \\
This study & $1.011(0.978-1.044)$ & $0.0 \%$ & 0.643 \\
\hline & & & \\
\hline
\end{tabular}

FIGURE 4 | The leave-one-out sensitivity analysis for overall analysis. The forest plot (A, B) table showed the effects for heterogeneity of each study. 

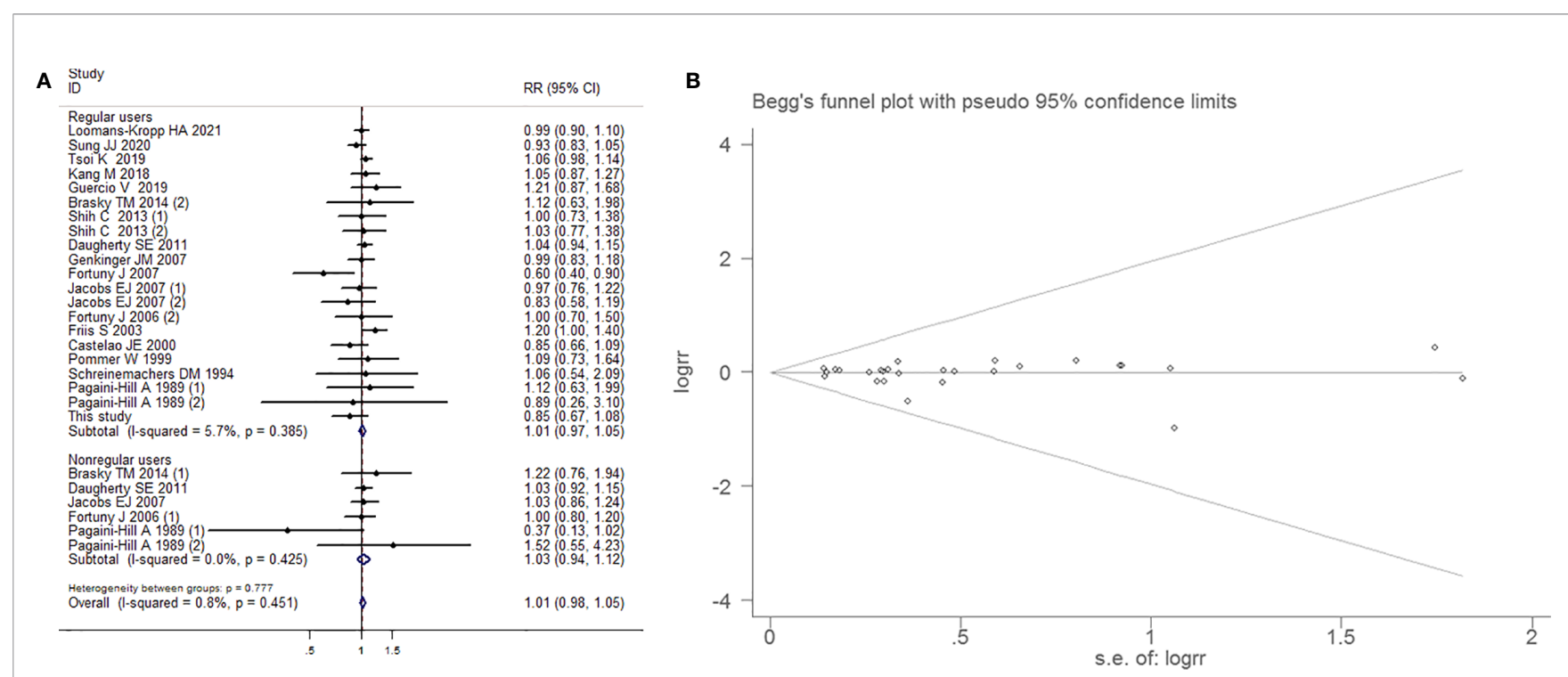

FIGURE 5 | Forest plot (A) and funnel plot (B) showing the association of aspirin intake and the risk of bladder cancer in subgroup analysis by whether regularly intake aspirin.

duration of use aspirin $\geq 5$ years $(\mathrm{RR}=0.923,95 \% \mathrm{CI}=0.806-1.054$, $P=0.245)$ and even $<5$ years $(R R=0.901,95 \% C I=0.771-1.06$, $P=0.192$ )were not associated with bladder cancer risk. There was no proof of significant publication bias by inspection of the funnel plot and formal statistical tests (Egger's test, $\mathrm{p}=0.064$; Begg's test, $P=0.272$; Figure 6).

\section{Subgroup Analysis by Sex}

As a slight degree of heterogeneity was found $\left(\mathrm{I}^{2}=38.0 \%\right.$, $P=0.088$ ), so a fixed-effects model was used. The results indicated no correlation between aspirin intake and BCa in either the male population $(R R=1.028,95 \% C I=0.958-1.102$,
$P=0.449)$ or the female population $(\mathrm{RR}=1.014$, 95\% $\mathrm{CI}=0.873$ $1.178, P=0.856)$. Both Begg's test $(P=0.837)$ and Egger's funnel plot asymmetry test $(P=0.971)$ indicated that there was no significant publication bias (Figure 7).

\section{Subgroup Analysis by Smoking Exposure}

Smoking exposure in bladder cancer risk assessment is extremely necessary. There was no testimony for heterogeneity $\left(\mathrm{I}^{2}=0.0 \%\right.$, $P=0.613)$. There were no apparent pertinence of aspirin and $\mathrm{BCa}$ embodied in the groups of non-smokers ( $R R=0.966,95 \%$ $\mathrm{CI}=0.845-1.104, P=0.610)$, former smokers $(\mathrm{RR}=1.073,95 \%$ $\mathrm{CI}=0.989-1.165, P=0.091)$ and current smokers $(\mathrm{RR}=0.896$,
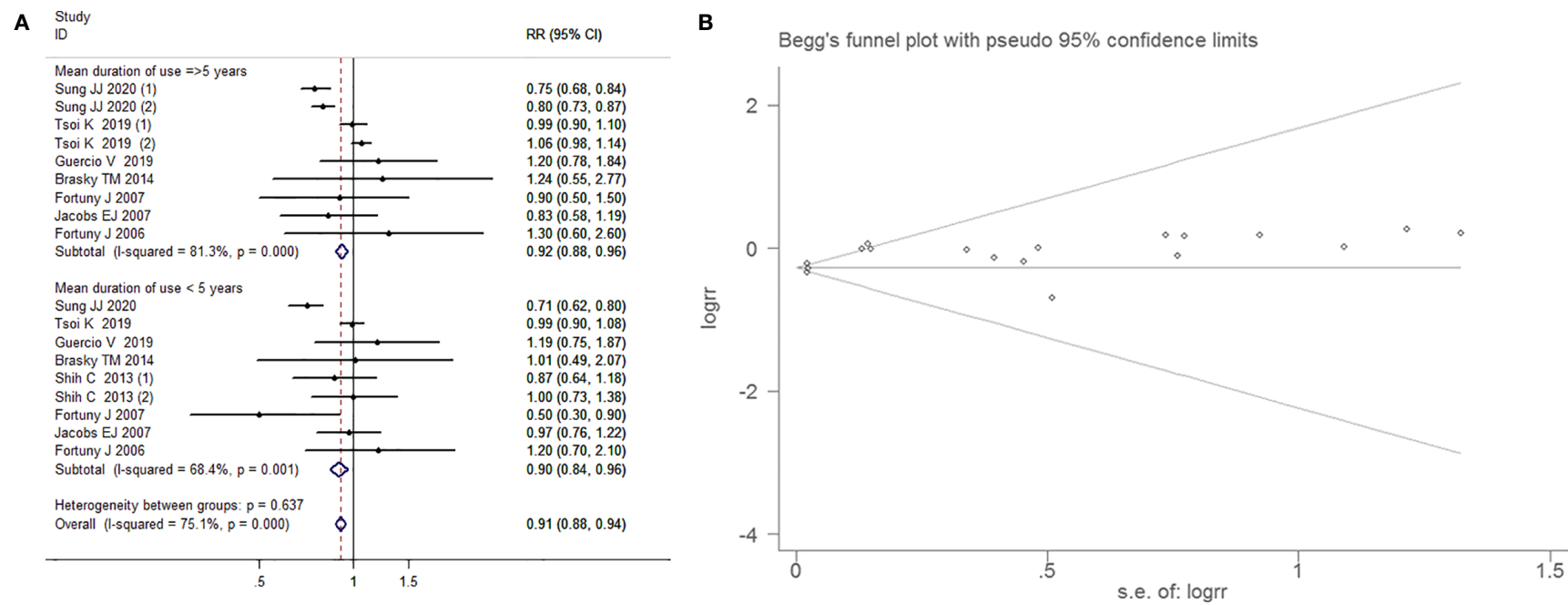

FIGURE 6 | Forest plot (A) and funnel plot (B) showing the association of aspirin intake and the risk of bladder cancer in subgroup analysis by the mean duration of aspirin use. 

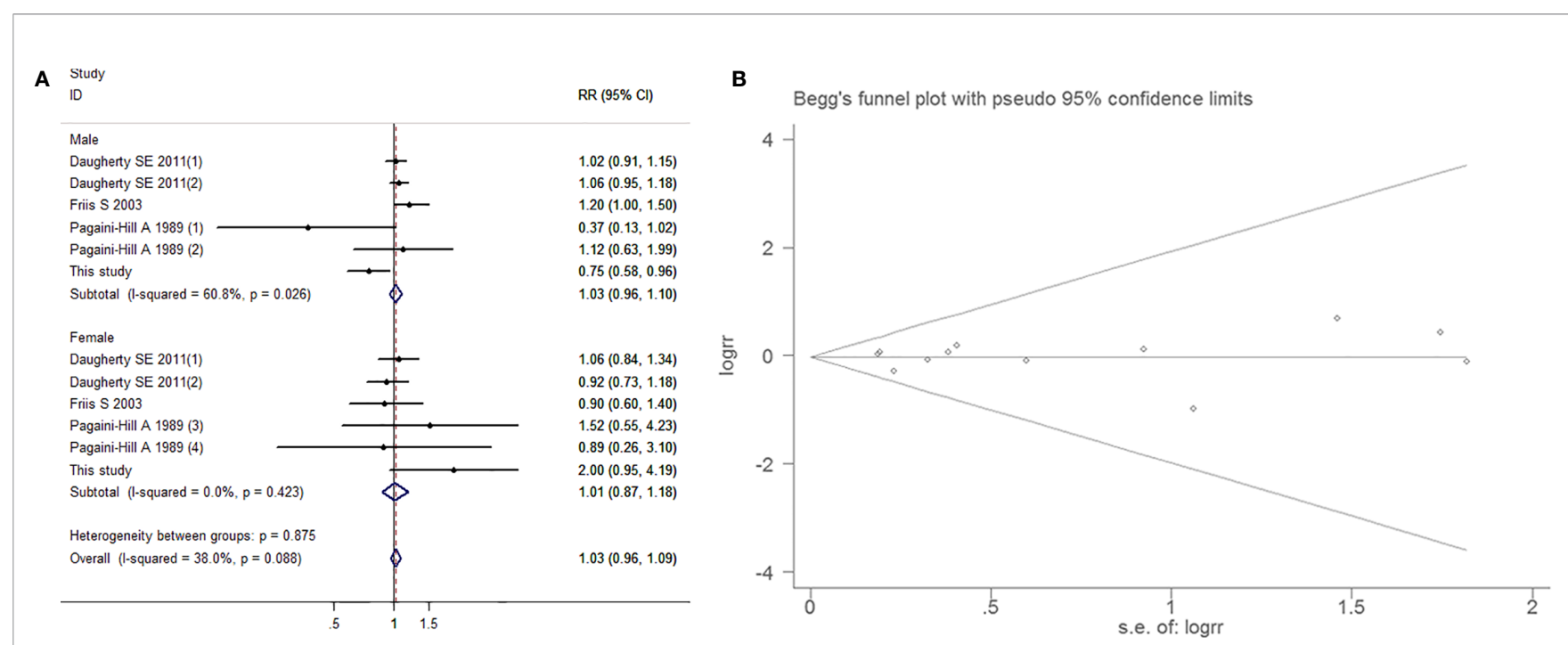

FIGURE 7 | Forest plot (A) and funnel plot (B) showing the association of aspirin intake and the risk of bladder cancer in subgroup analysis by gender.

95\% $\mathrm{CI}=0.777-1.032, P=0.128)$, the overall analysis results also showed no difference $(\mathrm{RR}=1.012,95 \% \mathrm{CI}=0.951-1.078, P=0.707)$. Publication bias was not obvious (Egger's test, $P=0.817$; Begg's test, $P=0.381$; Figure 8).

\section{Subgroup Analysis by Research Region}

Meta-analysis using a fixed-effects model $\left(\mathrm{I}^{2}=0.0 \%, P=0.590\right)$ suggested that aspirin intake had no significant influence on the prevention of $\mathrm{BCa}$ in multi-regions $(\mathrm{RR}=0.974,95 \% \mathrm{CI}=0.910$ 1.043, $P=0.456)$, Asian populations $(\mathrm{RR}=0.991,95 \% \mathrm{CI}=0.902$ $1.088, P=0.850)$, European populations ( $R R=1.112,95 \%$ $\mathrm{CI}=0.996-1.242, P=0.059)$ and North American populations $(\mathrm{RR}=1.000,95 \% \mathrm{CI}=0.948-1.055, P=0.990)$. There was no evidence of significant publication bias by inspection of the funnel plot and formal statistical tests (Egger's test, $\mathrm{p}=0.703$; Begg's test, $P=0.961$; Figure 9).

\section{Subgroup Analysis by Study Type}

Within 18 cohort studies, aspirin intake was not linked to a decreased risk of $\mathrm{BCa}(\mathrm{RR}=1.012,95 \% \mathrm{CI}=0.972-1.053, P=0.565)$. There was no evidence for heterogeneity $\left(\mathrm{I}^{2}=0.0 \%, P=0.590\right)$. Moreover, when the data collected from 13 case-control studies $(16,17)$ were pooled (Figure 10), there was no statistically significant association between aspirin administration and $\mathrm{BCa}$ $(\mathrm{RR}=1.000,95 \% \mathrm{CI}=0.944-1.058, P=0.989)$. No association between aspirin intake and $\mathrm{BCa}$ was also examined in other study type subgroup $(\mathrm{RR}=1.007,95 \% \mathrm{CI}=0.975-1.041, P=0.752)$ Begg's test $(P=0.752)$ and Egger's test $(P=0.744)$ showed that the
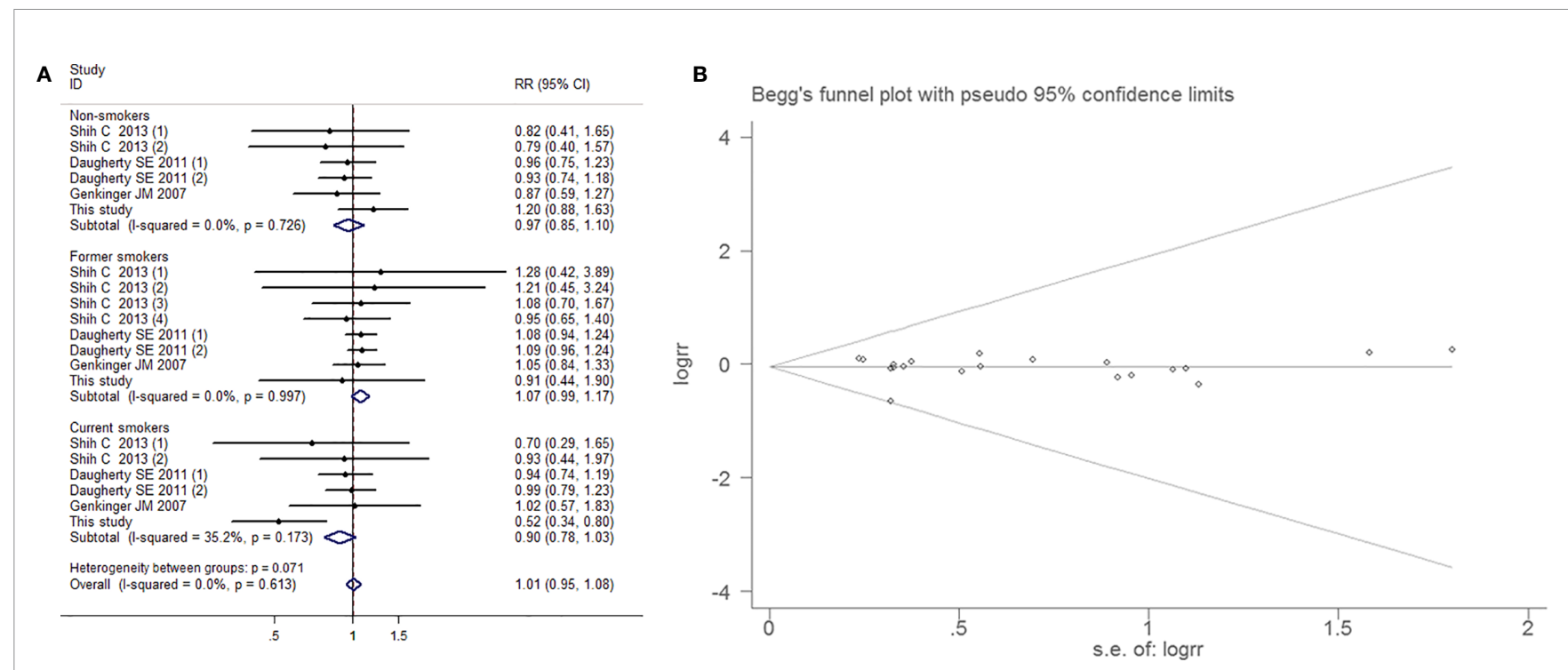

FIGURE 8 | Forest plot (A) and funnel plot (B) showing the association of aspirin intake and the risk of bladder cancer in subgroup analysis by smoking status. 

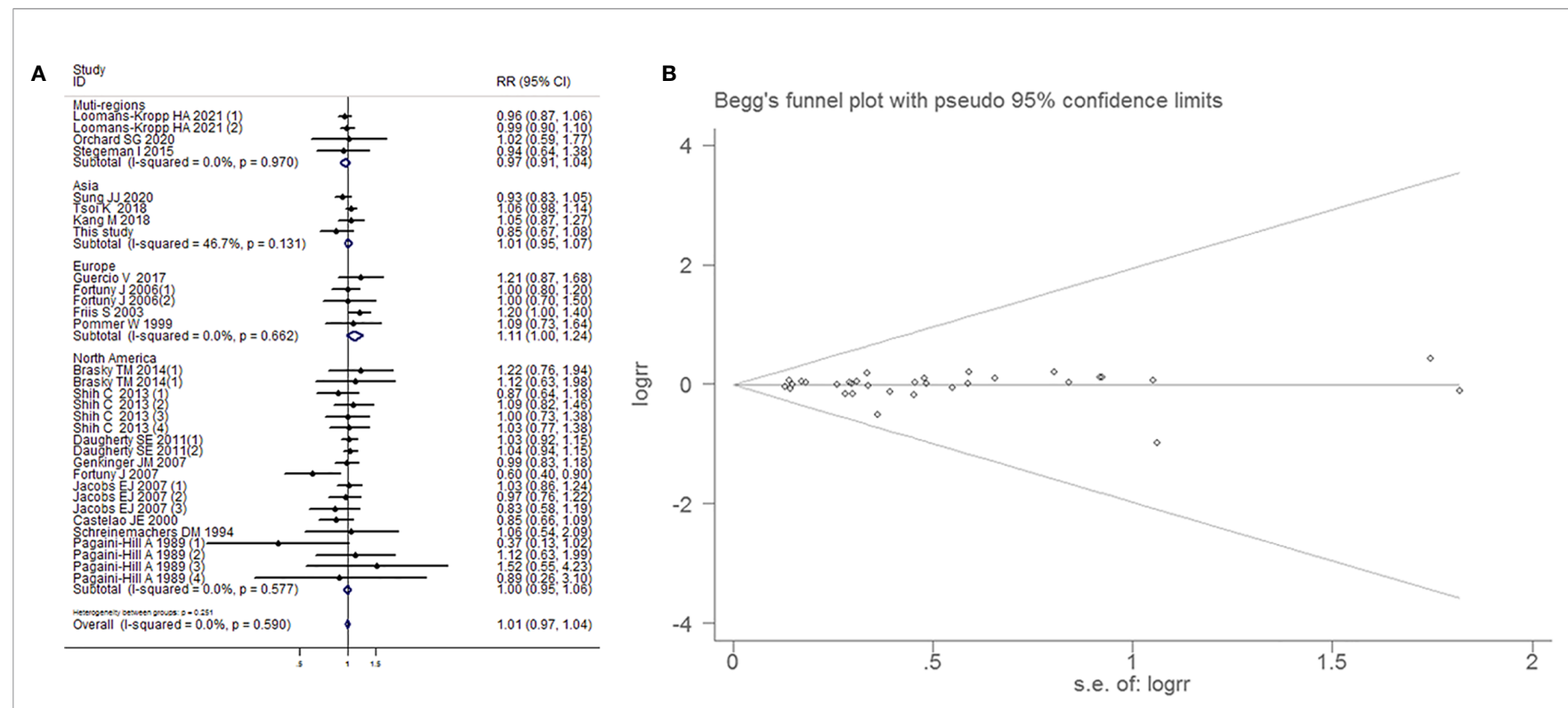

FIGURE 9 | Forest plot (A) and funnel plot (B) showing the association of aspirin intake and the risk of bladder cancer in subgroup analysis by region.

funnel plot distribution was symmetrical and that there was no significant publication bias.

\section{The Association Between Aspirin Intake and Outcomes of Surgery for BCa}

The Association Between Aspirin Intake and Intraoperative Conditions in Patients With $\mathrm{BCa}$

Four studies suggested the relationship between aspirin intake and intraoperative conditions, including mean loss of hemoglobin, mean duration of operation and blood transfusion rate. The low and moderate heterogeneity was observed in blood transfusion rate group ( $\mathrm{I} 2=0.0 \%, \mathrm{P}=0.814)$ and the mean duration of operation ( $\mathrm{I} 2=68.0 \%, \mathrm{P}=0.08)$ group, using fixedeffects models; while high heterogeneity was determined in exploring the association between aspirin intake and the mean loss of hemoglobin ( $\mathrm{I} 2=81.0 \%, \mathrm{P}=0.006)$ for $\mathrm{BCa}$ patients, and a random-effects model was applied. Compared with control group, aspirin intake had no impact on loss of hemoglobin with a combined $\mathrm{MD}$ of 0.08 ( $95 \% \mathrm{CI}=-0.32-0.48, P=0.68)$ and the mean duration of operation with a combined MD of -2.36 (95\% CI $=-22.36-17.63, P=0.820$ ). Moreover, there was no difference in blood transfusion rate during the resection of $\mathrm{BCa}$

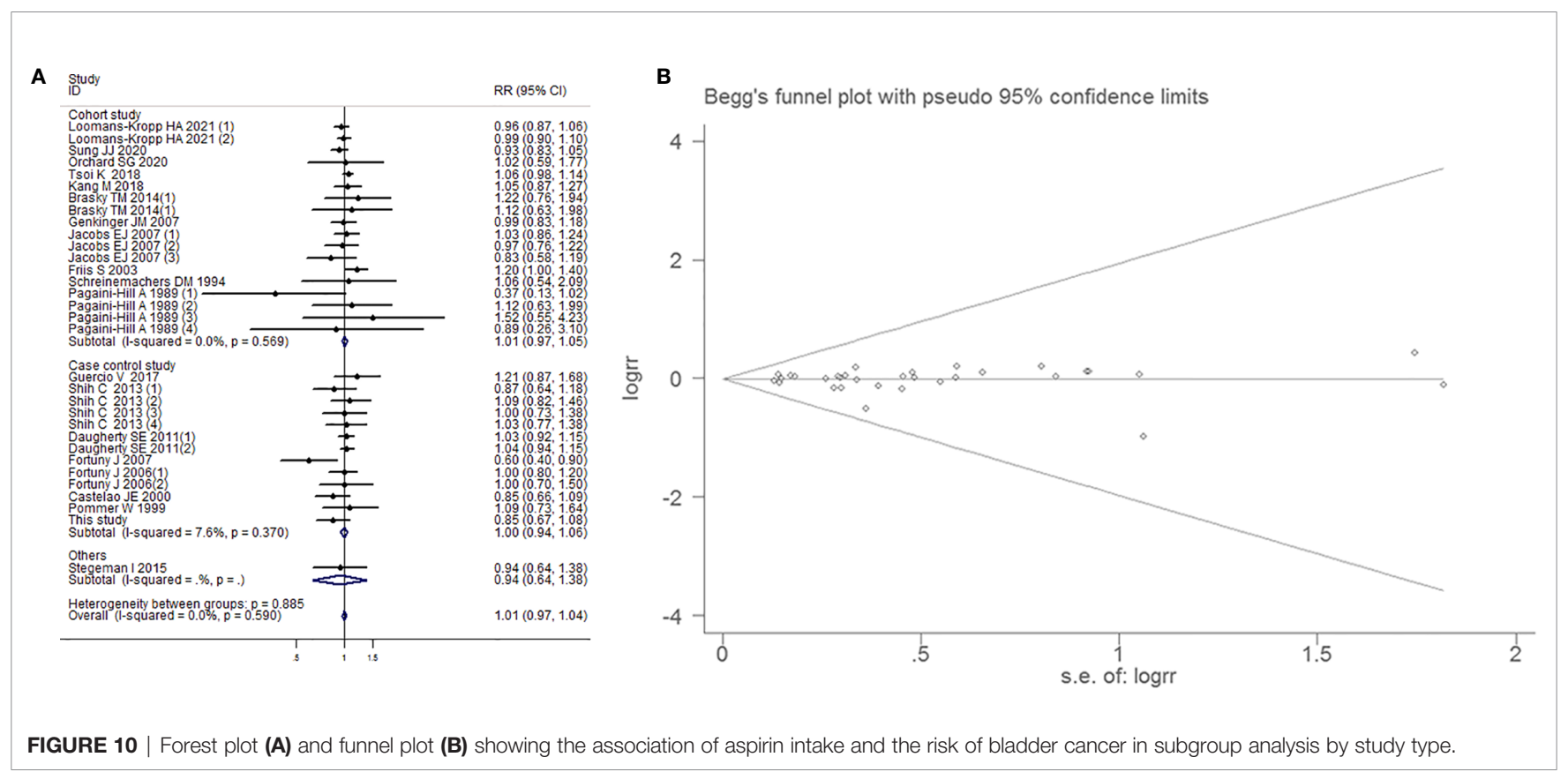


between the aspirin group and the control group ( $R R=1.147,95 \%$ $\mathrm{CI}=0.826-1.593, P=0.412$ ).

\section{The Association Between Aspirin Intake and Postoperative Complications in Patients With $\mathrm{BCa}$}

Three studies suggested the relationship between aspirin intake and postoperative complications including incidence of anycause rehospitalization and hemostatic operation. As low heterogeneity was detected in any-cause rehospitalization ( $\mathrm{I} 2=65.4 \%, \mathrm{P}=0.056)$ and hemostatic operation ( $\mathrm{I} 2=0.0 \%$, $\mathrm{P}=0.577)$ groups, fixed-effects models were used. Compared to control group, aspirin intake had no impact on incidence of any-cause rehospitalization $(\mathrm{RR}=1.12,95 \% \mathrm{CI}=0.80-1.57$, $P=0.797)$ and incidence of hemostatic operation $(\mathrm{RR}=1.86$, 95\% $\mathrm{CI}=0.40-8.73, \mathrm{P}=0.430)$. The above results showed in Figures $11 \mathrm{~A}-\mathrm{C}$.

\section{The Impact of Aspirin Intake on the Prognosis of Patients With Bladder Cancer}

\section{Aspirin Intake and the Survival of Patients With Bladder}

Cancer

Among 11 articles and our study including a total of $8825 \mathrm{BCa}$ patients with survival data, 6 studies investigated the relationship between aspirin intake and overall survival (OS) in BCa patients, and 4 studies reported cancer-specific survival (CSS). The random-effects model was used (Figure 12), as higher heterogeneity was detected among these studies $(P$-value for heterogeneity $\left.<0.001 ; \mathrm{I}^{2}=73.5 \%\right)$. No significantly decreased levels of OS were observed in BCa patients who consumed aspirin compared with the controls, with a combined HR of 1.026 (95\% $\mathrm{CI}=0.770-1.368, P=0.859)$. In contrast, aspirin intake had significant effects on the CSS of $\mathrm{BCa}$ patients ( $\mathrm{HR}=0.749,95 \%$ $\mathrm{CI}=0.646-0.869, P<0.001)$.
A

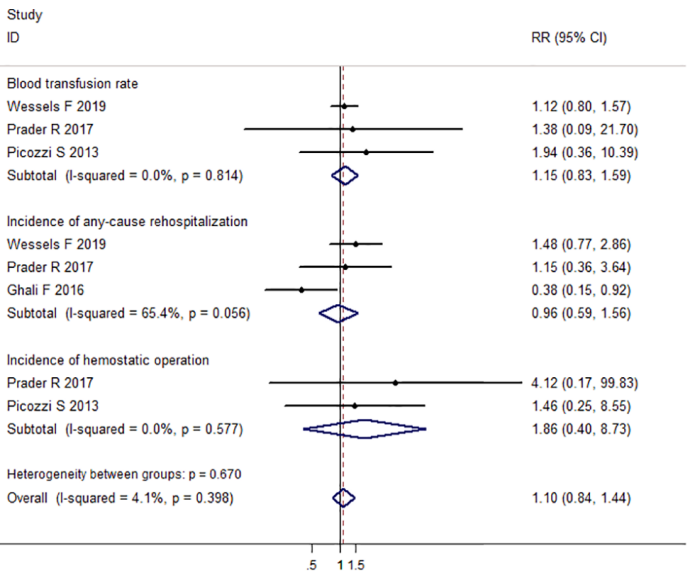

B

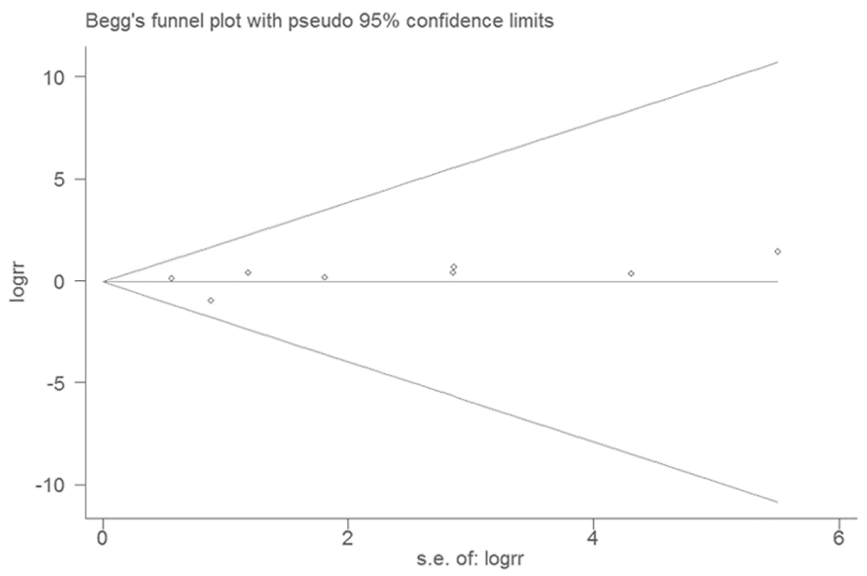

C

\begin{tabular}{|c|c|c|c|c|c|c|c|c|c|c|c|c|}
\hline \multirow[b]{2}{*}{ Study or Subgroup } & \multicolumn{3}{|c|}{ Aspirin group } & \multicolumn{3}{|c|}{ Control group } & & \multirow{2}{*}{$\begin{array}{l}\text { Mean Difference } \\
\text { IV. Random, } 95 \% \mathrm{Cl}\end{array}$} & \multirow{2}{*}{\multicolumn{4}{|c|}{$\begin{array}{l}\text { Mean Difference } \\
\text { IV. Random. } 95 \% \mathrm{Cl}\end{array}$}} \\
\hline & Mean & SD & Total & Mean & SD & Total & Weight & & & & & \\
\hline \multicolumn{13}{|c|}{ 1.4.1 Mean duration of operation } \\
\hline Picozzi S 2013 & 31 & 13.7 & 108 & 26 & 2.9 & 105 & $4.2 \%$ & $5.00[2.36,7.64]$ & & & - & \\
\hline Wessels F 2019 & 257.3 & 79.3 & 50 & 273.8 & 86.5 & 346 & $0.1 \%$ & $-16.50[-40.30,7.30]$ & & & & \\
\hline Subtotal $(95 \% \mathrm{Cl})$ & & & 158 & & & 451 & $4.3 \%$ & $-2.36[-22.36,17.63]$ & & & & \\
\hline \multirow{2}{*}{\multicolumn{13}{|c|}{$\begin{array}{l}\text { Heterogeneity: } \text { Tau }^{2}=156.52 ; \mathrm{Chi}^{2}=3.10, \mathrm{df}=1(P=0.08) ;\left.\right|^{2}=68 \% \\
\text { Test for overall effect: } Z=0.23(P=0.82)\end{array}$}} \\
\hline & & & & & & & & & & & & \\
\hline \multicolumn{13}{|c|}{ 1.4.2 Mean loss of haemoglobin } \\
\hline Picozzi S 2013 & -0.6 & 0.9 & 108 & -0.8 & 0.7 & 105 & $34.0 \%$ & $0.20[-0.02,0.42]$ & & & 中 & \\
\hline Prader R 2017 & -0.4 & 1.1 & 85 & -0.8 & 0.8 & 117 & $33.0 \%$ & $0.40[0.12,0.68]$ & & & 中 & \\
\hline Wessels F 2019 & 2.7 & 1.6 & 50 & 3.2 & 1.6 & 346 & $28.7 \%$ & $-0.50[-0.97,-0.03]$ & & & & \\
\hline Subtotal $(95 \% \mathrm{Cl})$ & & & 243 & & & 568 & $95.7 \%$ & $0.08[-0.32,0.48]$ & & & & \\
\hline \multicolumn{13}{|c|}{$\begin{array}{l}\text { Heterogeneity: } \text { Tau }^{2}=0.10 ; \mathrm{Chi}^{2}=10.37, \mathrm{df}=2(P=0.006) ; \mathrm{I}^{2}=81 \% \\
\text { Test for overall effect: } Z=0.41(P=0.68)\end{array}$} \\
\hline \multirow{2}{*}{\multicolumn{9}{|c|}{$\begin{array}{l}\text { Total }(95 \% \mathrm{Cl}) \\
\text { Heterogeneity: } \text { Tau }^{2}=0.24 ; \mathrm{Chi}^{2}=24.95, \mathrm{df}=4(\mathrm{P}<0.0001) ; \mathrm{I}^{2}=84 \%\end{array}$}} & & & & \\
\hline & & & & & & & & & -100 & & & 50 \\
\hline \multicolumn{13}{|c|}{$\begin{array}{ll}\text { Test for overall effect: } Z=0.87(P=0.38) & \text { Favours [Aspirin group] Favours [Control group] } \\
\text { Test for subaroun differences: } \mathrm{Chi}^{2}=0.06 . \mathrm{df}=1(\mathrm{P}=0.81) . \mathrm{I}^{2}=0 \% & \end{array}$} \\
\hline
\end{tabular}

FIGURE 11 | Forest plot (A) and funnel plot (B) showing the association of aspirin intake and the outcome of surgery, including blood transfusion rate, incidence of any-cause rehospitalization and the incidence of hemostatic operation; Forest plot (C) showing the association of aspirin intake and the outcome of surgery, including the mean duration of operation and mean loss of hemoglobin for BCa patients. 


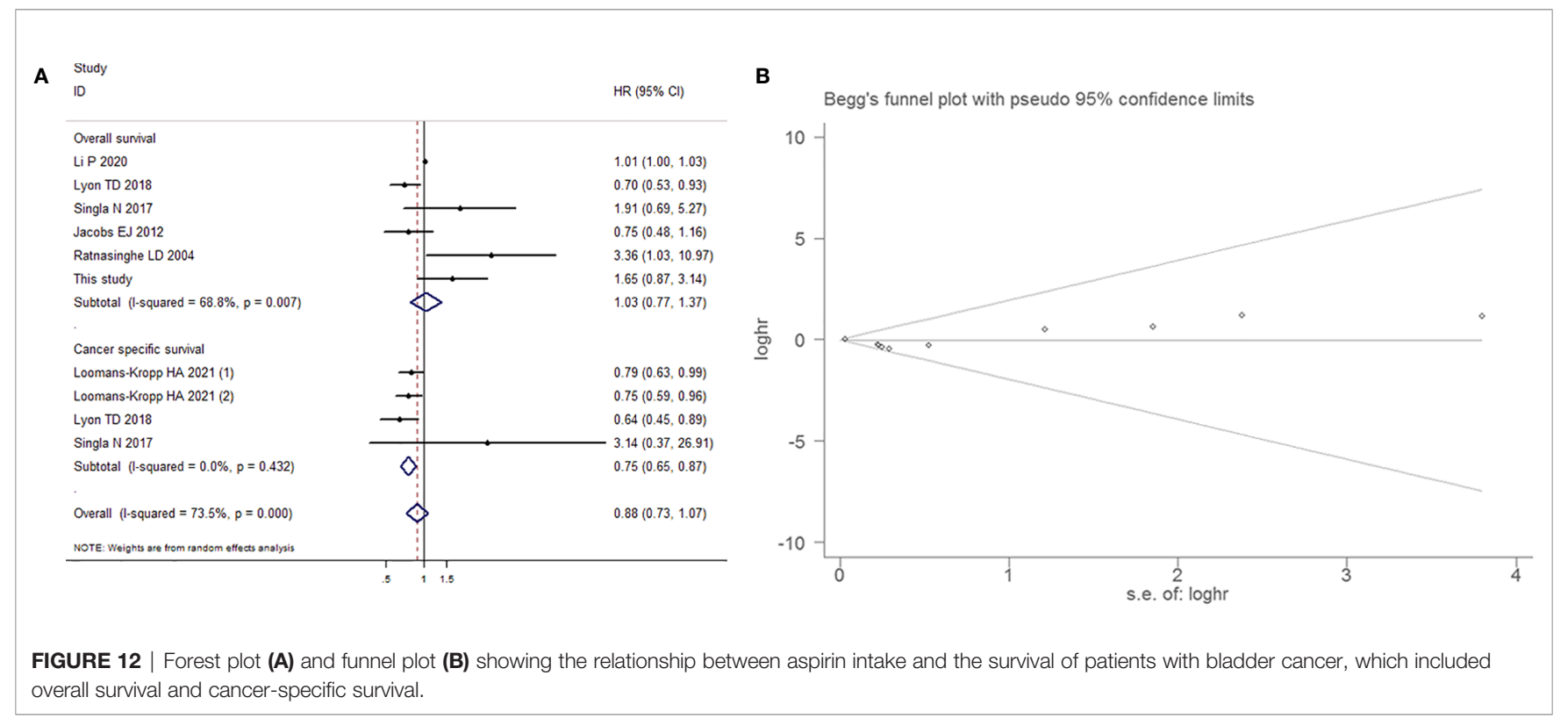

\section{Aspirin Intake and Recurrence, Progression and Metastasis of Patients With Bladder Cancer}

7 studies that reported the effect estimates of the association between aspirin intake and the recurrence, progression and metastasis of BCa. The random-effects model was applied, as the test for heterogeneity was significant $\left(\mathrm{I}^{2}=55.5 \%, P=0.013\right)$. We found that patients with aspirin intake did not have a significantly lower risk of $\mathrm{BCa}$ recurrence $(\mathrm{HR}=0.936,95 \%$ $\mathrm{CI}=0.667-1.313, P=0.701)$, progression $(\mathrm{HR}=0.922,95 \%$ $\mathrm{CI}=0.570-1.489, P=0.739)$ and metastasis $(\mathrm{HR}=0.960$, 95\% $\mathrm{CI}=0.679-1.358, P=0.817)$ than those without aspirin intake, as shown in Figure 13A. This result exhibited a low probability of publication bias, as determined by Egger's test $(P=0.798$, Figure 13B $)$.

\section{DISCUSSION}

Aspirin is a non-steroidal anti-inflammatory drug with a long history. It is suitable for antipyretic and analgesic use and is widely used in the prevention of cardiovascular thrombosis (18). Recent studies have found that the long-term regular use of aspirin can significantly reduce the incidence of colorectal cancer, gastric cancer, liver cancer and other malignant tumors and improve the survival of patients with its anticancer effects (62-65). A population-based case-control study analyzed data from $1121 \mathrm{BCa}$ cases and 2242 controls in New Hampshire and found that aspirin significantly reduced the risk of $\mathrm{BCa}$, especially for tumors containing TP53 mutations (33). Similarly, Castelao J et al. (31) illustrated that there was a
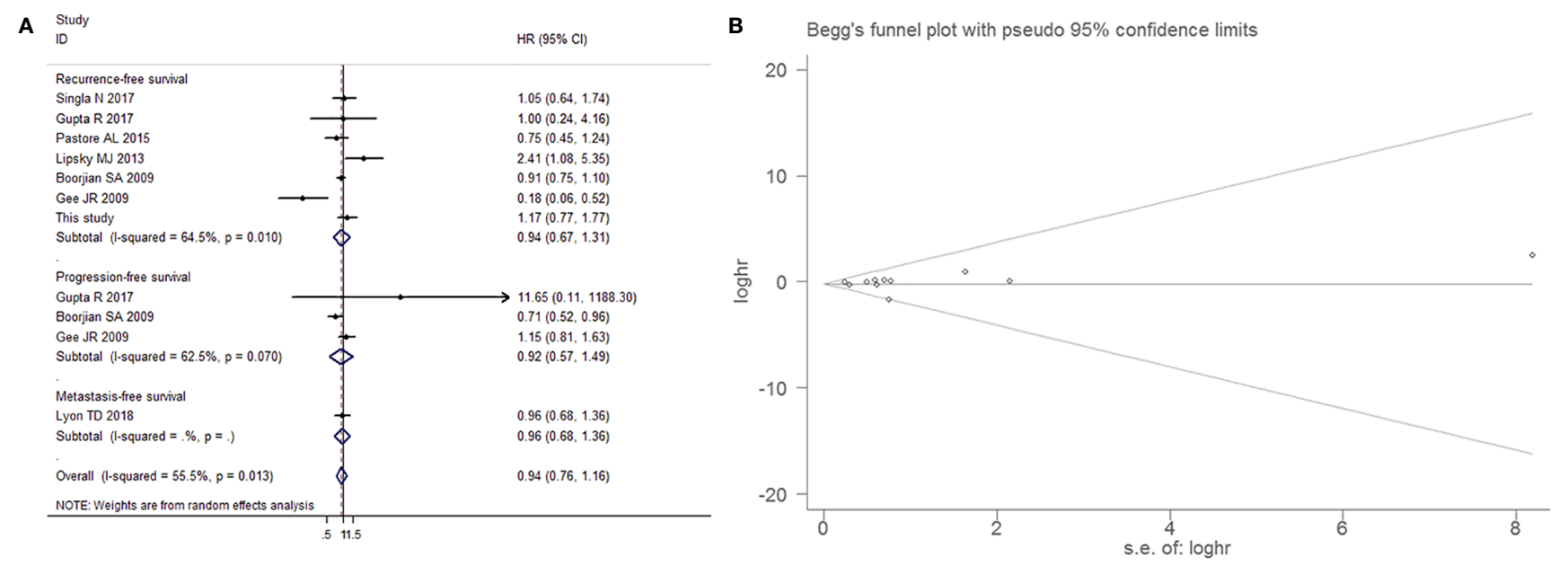

FIGURE 13 | Forest plot (A) and funnel plot (B) showing the relationship between aspirin intake and recurrence-free survival and progression-free survival of patients with bladder cancer. 
nonsignificant trend towards increased $\mathrm{BCa}$ risk in people with a longer duration of painkillers than in people who do not use painkillers, and regarding the effect of the correlation of different types of analgesics and $\mathrm{BCa}$ risk on the direction and strength of the obvious difference, aspirin showed weaker role. However, in a cohort study by Genkinger JM et al. (34). In the USA, there was no association between the frequency and dose of aspirin and $\mathrm{BCa}$ risk, which was not altered by known risk factors such as age, smoking or total fluid intake. To compensate for the lack of related research focusing on the population in Northeast China, a retrospective single-center case-control study analyzed data from 1121 BCa cases and 2242 controls in Northeast China was established to explore the association between the incidence of $\mathrm{BCa}$ and aspirin intake. Although we found several susceptibility factors were associated with strong risk of $\mathrm{BCa}$, including gender (OR=1.263; $P=0.028)$; marital status $(\mathrm{OR}=0.165 ; P<0.001)$; current smoking status $(\mathrm{OR}=2.360 ; P<0.001)$; current alcohol use $(\mathrm{OR}=0.615 ; P<0.001)$; former alcohol use $(\mathrm{OR}=0.314$; $P<0.001)$ and history of cardiovascular disease $(\mathrm{OR}=0.212$; $P<0.001)$, regular use of aspirin was not associated with a reduced risk of $\mathrm{BCa}(P=0.175)$. As studies of aspirin use and the risk of BCa have yielded mixed results, we further conducted meta-analyses and found that patients with aspirin intake did not have a significantly lower risk of BCa than those without aspirin intake after combining nineteen included articles and our study with more than $39524 \mathrm{BCa}$ patients $(P=0.671)$. Subgroup analysis by whether regular use of aspirin, by the mean duration of use of aspirin, by sex, by smoking exposure, by research region and by study type suggested that aspirin intake had no significant influence on the prevention of BCa.

Interestingly, in our case control study, subgroup analyses stratified by sex showed that there was no correlation between aspirin intake and the risk of $\mathrm{BCa}$ in female patients, however, the male population who regularly took aspirin had a lower incidence of $\mathrm{BCa}(\mathrm{OR}=0.748 ; P=0.021)$. While considering the limited sample size and ethnic specificity, several explanations may help us better understand the above result. Androgens/ Androgen Receptor (AR) system is considered as a central link to physiology and behaviors in male. Similarly, the development of clinical pathology of male malignant tumors could originate from this system (66). There were several studies identifying high expression of ARs in bladder cancer, suggesting that ARs could act as potential markers for monitoring and regulating malignant biological behaviors of $\mathrm{BCa}$ including metastasis, and recurrence $(67,68)$. The possible mechanisms contain DNA damage repair, promotion of p53 signaling, or activation of EGFR/ERBB2 pathway, etc. (69). As a mainstream therapy for advanced prostate cancer, androgen deprivation therapy (ADT) was founded having important potential in improving survival of bladder cancer, particularly non-muscle-invasive $\mathrm{BCa}$ (70). To our knowledge, antagonist of ARs, consisting of cyproterone, enzalutamide, docetaxel and so forth, is common medicine in ADT. Among these, as a potential application of ADT, aspirin could decrease the mRNA and protein expression of ARs, which has dose-dependence and time-dependence (71). Thereupon, we speculate that in male population, aspirin maybe significantly down-regulate ARs to inhibit the Androgens/Androgen Receptor system and subsequently suppress incidence of $\mathrm{BCa}$, which need further molecular biological validation.

Meanwhile, it should be noted that subgroup analyses stratified by smoking status in our case control study found a significant reduction in the risk of $\mathrm{BCa}$ in current smokers with aspirin intake $(\mathrm{OR}=0.522 ; P=0.002)$, not in nonsmokers $(P=0.252)$ or former smokers $(P=0.807)$. Smoking and daily aspirin use are both risk factors for cancer. Some research indicates that aspirin usage in smokers is correlated with an increased risk of developing cancer, which could nullify the protective function of aspirin (72-74). Wang X et al. (73). found that aspirin use was related to a $29 \%$ lower CRC risk among never-smokers, compared to $17 \%$ lower CRC risk among smokers above median pack-years, indicating that heavy smokers could not be more favorable for protective role of aspirin against colorectal cancer than non- smokers. As cigarette was found to be more strongly associated with colorectal carcinoma which arise from serrated polyp pathway related to microsatellite instability, it was related to an increased risk of polyps in the left colon (75). While aspirin intake lowered the risk of serrated polyps in the right colon, indicating different subsites of colon cancer may be influenced by.aspirin and smoking (75). As playing role on platelet hyper-reactivity, smoking was strongly associated with increased risk of aspirin resistance, suggesting that the effect of aspirin may rely on independent carcinogenesis or progression (76) pathways of colorectal carcinoma among smokers and non-smokers. In breast cancer, cigarette smoking and aspirin/NSAID use interacted to affect breast cancer-specific mortality. Slattery ML et al. (76) reported that the strongest associations were observed for the interaction between cigarette smoking and aspirin intake with JAK/STAT signaling pathway including JAK2, STAT3, STAT5a, and STAT5b which were critical for cell development, cell proliferation, and apoptosis of breast cancer. As SOCS suppressed the signaling. Nicotine which were found in cigarette smoke condensates and activated the JAK2/STAT3 pathway (77), rs3816997 of SOSC2 may interacted with cigarette smoking and aspirin intake.

The prognostic value of aspirin use on monitor the intraoperative and postoperative outcome of $\mathrm{BCa}$ patients was also attracted increasing attention from scholars. After follow up $1121 \mathrm{BCa}$ patients, we did not find that patients with a history of aspirin intake had a markedly longer overall or recurrence-free survival than those with no history of aspirin intake. Cox regression model did not indicate a history of aspirin intake was not an independent factor for overall or recurrence-free survival. Stratified analysis by sex showed no correlation between aspirin intake and the recurrence or survival of $\mathrm{BCa}$ for either male or female patients. Interestingly, we found that aspirin intake $(\mathrm{HR}=3.876 ; P=0.019)$ and type of surgery $(\mathrm{HR}=1.685$; $P=0.010)$ were significantly associated with overall survival in BCa patients younger than 68 years old. In the people who regularly used aspirin, majority of them has the history of coagulation abnormalities, consisting of platelet abnormalities and fibrinolysis (78-80). And coagulation abnormalities have 
long been closely related with the cardiovascular or cerebrovascular diseases, which are mostly found in the elderly and increased overall mortality considerably (81, 82). In addition, various of selection for statistics method may cause discrepancy the analysis outcomes.

Relative to our negative result about the effects of aspirin on tumor recurrence, a case-control study from Italy and a retrospective study from the USA showed a significant association between aspirin and recurrence in patients with BCa $(55,61)$. In the study of Gee JR (55), the 5-year RFS of aspirin users was $64.3 \%$, which was significantly higher than that of non-aspirin users (26.9\%), even after multivariate analysis adjusted for other factors. Considering the effect of aspirin on the survival rate of cancer patients, Lyon TD's study (59) found that daily aspirin significantly improved survival outcomes after radical resection. It has also been observed that patients receiving low-dose aspirin had significantly better outcomes than patients receiving high-dose aspirin and those without aspirin. In contrast, a cohort study from the United States found no significant association between aspirin use and the overall survival of BCa patients (52). In addition, a prospective study by Singla $\mathrm{N}$ et al. (58) showed that the use of aspirin does not affect the survival of patients with any tumors, including CSS, OS, recurrence-free survival and cystectomy-free survival, regardless of the dose ( 81 or 325 milligrams a day). In response to these mixed findings, we performed a metaanalysis to investigate the impact of aspirin intake on the prognosis of patients with $\mathrm{BCa}$ and found that aspirin had no significant effects on the OS and CSS of BCa patients. In addition, patients with aspirin intake did not have a significantly lower risk of $\mathrm{BCa}$ recurrence, progression and metastasis than those without aspirin intake. We also found that there was no difference in blood transfusion rate, loss of hemoglobin, mean duration of operation, any-cause rehospitalization and incidence of any-cause rehospitalization during the resection of $\mathrm{BCa}$ between the aspirin group and the control group. Until now, available data have not supported a connection between aspirin exposure and the intraoperative situation and postoperative prognosis of BCa patients despite few prior studies.

Our limitations are as follows: one limitation is that this casecontrol study is a single-center study, which may lead to certain bias or heterogeneity. To the greatest extent possible to avoid such shortcomings or loopholes, we performed a meta-analysis to investigate the relationship between aspirin intake and the risk and prognosis of $\mathrm{BCa}$. Some included studies did not provide available values of $\mathrm{HR}, \mathrm{RR}$ or OR from multivariate analysis, so we performed calculations from the univariate data and compared them through formula calculations. The statistical methods we used cannot replace all the research methods. The conclusions we obtained without correlation are limited to the scope of our research, which may have some statistical errors (83, 84). Second, we only focused on researching patients who regularly consumed aspirin. Due to the limited available information from clinical data, stratification analysis according to different doses or durations was not conducted. The above factors may influence the results regarding the connection between the risk of $\mathrm{BCa}$ and the use of aspirin (10), which will be one of the focuses of our future research. Third, both our casecontrol study and meta-analysis showed no differences between aspirin intake and the risk and prognosis of BCa. However, previous in vitro studies have shown that aspirin may play a role as a chemopreventive agent in the $\mathrm{OH}-\mathrm{BBN} / \mathrm{BDF} \mathrm{BCa}$ model (85), which suggests that there is heterogeneity between human epidemiological experiments and in vitro cell experiments.

\section{CONCLUSION AND OUTLOOK}

Although aspirin has been predicted to be protective against various of tumors, differences in tumor origin and tissue specificity are bound to influence the results, which needed virtual simulated human microenvironment to explore whether aspirin can prevent or monitor BCa. Meanwhile, multi-center, large-sample, prospective studies are also needed. Advances in cancer biology clearly indicate that the development of malignant tumors is the result of complex interactions and the integration of gene expression, proteome and metabolome changes, involving genetics, microbes, diet, drugs (86, 87), and other factors such as different living conditions, exposure factors and ethnic differences (88). In the age of precision oncology, individual cancer treatment should be personalized based on genetic and environmental factors. In addition, aspirin, as a sensitizer, can increase the therapeutic effect of chemotherapy for cancers of the colon and stomach, while there are few studies in the urinary system, which will be a promising research direction. As a continuation of this study, it is necessary to further explore pathological examinations, immune parameters, tumor molecular markers and other aspects from the database, which contributes greatly to the development of $\mathrm{BCa}$ treatment.

\section{DATA AVAILABILITY STATEMENT}

The datasets generated for our case-control study are available on request to the corresponding authors. Additionally, publicly available datasets for meta-analysis in our study could be searched in the PubMed, Embase, Ovid Medicine, Cochrane Library and Scopus databases.

\section{ETHICS STATEMENT}

This study was approved by the institutional review committee of the Second Affiliated Hospital of Dalian Medical University and written informed consent was obtained from each patient or their next of kin (Approval Ref. No. KY2018-120).

\section{AUTHOR CONTRIBUTIONS}

$\mathrm{BF}, \mathrm{XL}$, and GW contributed to the study concept and design, undertook project leadership and guaranteed this work. YH, HL, HJ, MFS, ST, WX, QL, TH, ZY, and RZ were responsible for data 
collection and interpretation. ZY and RZ controlled quality of data and algorithms. BF, AM, YH, HJ, and ST analyzed data and interpreted the data. BF, GW, HL, HJ, and MS wrote the first draft of the manuscript. BF, HY, and AM reviewed and revised the manuscript. All authors contributed to the article and approved the submitted version.

\section{FUNDING}

This study was supported by the National Natural Science Foundation of China (81972831 and 31800787), the United Fund of the Second Hospital of Dalian Medical University and

\section{REFERENCES}

1. Dobruch J, Daneshmand S, Fisch M, Lotan Y, Noon AP, Resnick MJ, et al. Gender and Bladder Cancer: A Collaborative Review of Etiology, Biology, and Outcomes. Eur Urol (2016) 69:300-10. doi: 10.1016/j.eururo. 2015.08.037

2. Antoni S, Ferlay J, Soerjomataram I, Znaor A, Jemal A, Bray F. Bladder Cancer Incidence and Mortality: A Global Overview and Recent Trends. Eur Urol (2017) 71:96-108. doi: 10.1016/j.eururo.2016.06.010

3. Smith ND, Prasad SM, Patel AR, Weiner AB, Pariser JJ, Razmaria A, et al. Bladder Cancer Mortality in the United States: A Geographic and Temporal Analysis of Socioeconomic and Environmental Factors. J Urol (2016) 195:290-6. doi: 10.1016/j.juro.2015.07.091

4. Galsky MD. Bladder Cancer in 2017: Advancing Care Through Genomics and Immune Checkpoint Blockade. Nat Rev Urol (2018) 15:71-2. doi: 10.1038/ nrurol.2017.199

5. Pang C, Guan Y, Li H, Chen W, Zhu G. Urologic Cancer in China. Jpn J Clin Oncol (2016) 46:497-501. doi: 10.1093/jjco/hyw034

6. Liu X, Jiang J, Yu C, Wang Y, Sun Y, Tang J, et al. Secular Trends in Incidence and Mortality of Bladder Cancer in China, 1990-2017: A Joinpoint and AgePeriod-Cohort Analysis. Cancer Epidemiol (2019) 61:95-103. doi: 10.1016/ j.canep.2019.05.011

7. Alfred Witjes J, Lebret T, Compérat EM, Cowan NC, De Santis M, Bruins HM, et al. Updated 2016 EAU Guidelines on Muscle-Invasive and Metastatic Bladder Cancer. Eur Urol (2017) 71:462-75. doi: 10.1016/j.eururo.2016. 06.020

8. van Kessel K, van der Keur KA, Dyrskjøt L, Algaba F, Welvaart N, Beukers W, et al. Molecular Markers Increase Precision of the European Association of Urology Non-Muscle-Invasive Bladder Cancer Progression Risk Groups. Clin Cancer Res (2018) 24:1586-93. doi: 10.1158/1078-0432.CCR-17-2719

9. Masic S, Smaldone MC. Treatment Delays for Muscle-Invasive Bladder Cancer. Cancer (2019) 125:1973-5. doi: 10.1002/cncr.32047

10. Oţelea MR, Jinga V, Raşcu AŞC, Pleşea IE, Petrescu AN, Mitrache LE, et al. Occupational Exposure to Urinary Bladder Carcinogens - Risk Factors, Molecular Mechanisms and Biomarkers. Rom J Morphol Embryol (2018) 59:1021-32.

11. Zeegers MP, Kellen E, Buntinx F, van den Brandt PA. The Association Between Smoking, Beverage Consumption, Diet and Bladder Cancer: A Systematic Literature Review. World J Urol (2004) 21:392-401. doi: 10.1007/ s00345-003-0382-8

12. Villanueva CM, Cantor KP, Grimalt JO, Malats N, Silverman D, Tardon A, et al. Bladder Cancer and Exposure to Water Disinfection by-Products Through Ingestion, Bathing, Showering, and Swimming in Pools. Am J Epidemiol (2007) 165:148-56. doi: 10.1093/aje/kwj364

13. Barry KH, Jones RR, Cantor KP, Beane Freeman LE, Wheeler DC, Baris D, et al. Ingested Nitrate and Nitrite and Bladder Cancer in Northern New England. Epidemiology (2020) 31:136-44. doi: 10.1097/EDE. 0000000000001112

14. Masaoka H, Matsuo K, Sawada N, Yamaji T, Goto A, Shimazu T, et al. Alcohol Consumption and Bladder Cancer Risk With or Without the Flushing
Dalian Institute of Chemical Physics, Chinese Academy of Sciences (UF-QN-202004), the Dalian High-level Talents Innovation Support Program (2019RQ014) and the Doctoral Research Startup Foundation of the Second Hospital of Dalian Medical University (DY2Y201704).

\section{ACKNOWLEDGMENTS}

We thank professor Xueyan Xia of Dalian Medical University Library for her generous support and direction. In addition, we would like to thank all members of the study team, the patients and their family for their contributions with our work.

Response: The Japan Public Health Center-Based Prospective Study. Int J Cancer (2017) 141:2480-8. doi: 10.1002/ijc.31028

15. Tuccori M, Filion KB, Yin H, Yu OH, Platt RW, Azoulay L. Pioglitazone Use and Risk of Bladder Cancer: Population Based Cohort Study. BMJ (2016) 352: i1541. doi: 10.1136/bmj.i1541

16. Hu J, Chen JB, Cui Y, Zhu YW, Ren WB, Zhou X, et al. Association of Metformin Intake With Bladder Cancer Risk and Oncologic Outcomes in Type 2 Diabetes Mellitus Patients: A Systematic Review and Meta-Analysis. Med (Baltimore) (2018) 97:e11596. doi: 10.1097/MD.0000000000011596

17. Capodanno D, Angiolillo DJ. Aspirin for Primary Cardiovascular Risk Prevention and Beyond in Diabetes Mellitus. Circulation (2016) 134:157994. doi: 10.1161/CIRCULATIONAHA.116.023164

18. Song Y, Zhong X, Gao P, Zhou C, Shi J, Wu Z, et al. Aspirin and Its Potential Preventive Role in Cancer: An Umbrella Review. Front Endocrinol (Lausanne) (2020) 11:3. doi: 10.3389/fendo.2020.00003

19. Risch HA, Lu L, Streicher SA, Wang J, Zhang W, Ni Q, et al. Aspirin Use and Reduced Risk of Pancreatic Cancer. Cancer Epidemiol Biomarkers Prev (2017) 26:68-74. doi: 10.1158/1055-9965.EPI-16-0508

20. Stopsack KH, Gonzalez-Feliciano AG, Peisch SF, Downer MK, Gage RA, Finn S, et al. A Prospective Study of Aspirin Use and Prostate Cancer Risk by TMPRSS2:ERG Status. Cancer Epidemiol Biomarkers Prev (2018) 27:1231-3. doi: 10.1158/1055-9965.EPI-18-0510

21. Moyad MA. An Introduction to Aspirin, NSAids, and COX-2 Inhibitors for the Primary Prevention of Cardiovascular Events and Cancer and Their Potential Preventive Role in Bladder Carcinogenesis: Part II. Semin Urol Oncol (2001) 19:306-16.

22. Nath N, Vassell R, Chattopadhyay M, Kogan M, Kashfi K. Nitro-Aspirin Inhibits MCF-7 Breast Cancer Cell Growth: Effects on COX-2 Expression and Wnt/beta-Catenin/TCF-4 Signaling. Biochem Pharmacol (2009) 78:1298-304. doi: 10.1016/j.bcp.2009.06.104

23. Henry WS, Laszewski T, Tsang T, Beca F, Beck AH, McAllister SS, et al. Aspirin Suppresses Growth in PI3K-Mutant Breast Cancer by Activating AMPK and Inhibiting Mtorc1 Signaling. Cancer Res (2017) 77:790-801. doi: 10.1158/0008-5472.CAN-16-2400

24. Pozzoli G, Petrucci G, Navarra P, Marei HE, Cenciarelli C. Aspirin Inhibits Proliferation and Promotes Differentiation of Neuroblastoma Cells via p21Waf1 Protein Up-Regulation and Rb1 Pathway Modulation. J Cell Mol Med (2019) 23:7078-87. doi: 10.1111/jcmm.14610

25. Di Maso M, Bosetti C, La Vecchia C, Garavello W, Montella M, Libra M, et al. Regular Aspirin Use and Nasopharyngeal Cancer Risk: A Case-Control Study in Italy. Cancer Epidemiol (2015) 39:545-7. doi: 10.1016/j.canep. 2015.04.012

26. Wang Y, Shen C, Ge J, Duan H. Regular Aspirin Use and Stomach Cancer Risk in China. Eur J Surg Oncol (2015) 41:801-4. doi: 10.1016/j.ejso. 2015.02.006

27. Khalaf N, Yuan C, Hamada T, Cao Y, Babic A, Morales-Oyarvide V, et al. Regular Use of Aspirin or Non-Aspirin Nonsteroidal Anti-Inflammatory Drugs Is Not Associated With Risk of Incident Pancreatic Cancer in Two Large Cohort Studies. Gastroenterology (2018) 154:1380-90. doi: 10.1053/ j.gastro.2017.12.001 
28. Sterne JA, Hernán MA, Reeves BC, Savović J, Berkman ND, Viswanathan M, et al. ROBINS-I: A Tool for Assessing Risk of Bias in non-Randomised Studies of Interventions. BMJ (2016) 355:i4919. doi: 10.1136/bmj.i4919

29. Paganini-Hill A, Chao A, Ross RK, Henderson BE. Aspirin Use and Chronic Diseases: A Cohort Study of the Elderly. BMJ (1989) 299:1247-50. doi: 10.1136/bmj.299.6710.1247

30. Schreinemachers DM, Everson RB. Aspirin Use and Lung, Colon, and Breast Cancer Incidence in a Prospective Study. Epidemiology (1994) 5:138-46. doi: 10.1097/00001648-199403000-00003

31. Castelao JE, Yuan JM, Gago-Dominguez M, Yu MC, Ross RK. Non-Steroidal Anti-Inflammatory Drugs and Bladder Cancer Prevention. Br J Cancer (2000) 82:1364-9. doi: 10.1054/bjoc.1999.1106

32. Fortuny J, Kogevinas M, Garcia-Closas M, Real FX, Tardón A, Garcia-Closas $\mathrm{R}$, et al. Use of Analgesics and Nonsteroidal Anti-Inflammatory Drugs, Genetic Predisposition, and Bladder Cancer Risk in Spain. Cancer Epidemiol Biomarkers Prev (2006) 15:1696-702. doi: 10.1158/10559965.EPI-06-0038

33. Fortuny J, Kogevinas M, Zens MS, Schned A, Andrew AS, Heaney J, et al. Analgesic and Anti-Inflammatory Drug Use and Risk of Bladder Cancer: A Population Based Case Control Study. BMC Urol (2007) 7:13. doi: 10.1186/ 1471-2490-7-13

34. Genkinger JM, De Vivo I, Stampfer MJ, Giovannucci E, Michaud DS. Nonsteroidal Antiinflammatory Drug Use and Risk of Bladder Cancer in the Health Professionals Follow-Up Study. Int J Cancer (2007) 120:2221-5. doi: 10.1002/ijc.22546

35. Daugherty SE, Pfeiffer RM, Sigurdson AJ, Hayes RB, Leitzmann M, Schatzkin A, et al. Nonsteroidal Antiinflammatory Drugs and Bladder Cancer: A Pooled Analysis. Am J Epidemiol (2011) 173:721-30. doi: 10.1093/aje/kwq437

36. Shih C, Hotaling JM, Wright JL, White E. Long-Term NSAID Use and Incident Urothelial Cell Carcinoma in the VITamins and Lifestyle (VITAL) Study. Urol Oncol (2013) 31:1689-95. doi: 10.1016/j.urolonc.2012.06.001

37. Guercio V, Turati F, Bosetti C, Polesel J, Serraino D, Montella M, et al. Bladder Cancer Risk in Users of Selected Drugs for Cardiovascular Disease Prevention. Eur J Cancer Prev (2019) 28:76-80. doi: 10.1097/CEJ.0000000000000419

38. Tsoi K, Ho J, Chan F, Sung J. Long-Term Use of Low-Dose Aspirin for Cancer Prevention: A 10-Year Population Cohort Study in Hong Kong. Int J Cancer (2019) 145:267-73. doi: 10.1002/ijc.32083

39. Loomans-Kropp HA, Pinsky P, Umar A. Evaluation of Aspirin Use With Cancer Incidence and Survival Among Older Adults in the Prostate, Lung, Colorectal, and Ovarian Cancer Screening Trial. JAMA Netw Open (2021) 4: e2032072. doi: 10.1001/jamanetworkopen.2020.32072

40. Orchard SG, Lockery JE, Gibbs P, Polekhina G, Wolfe R, Zalcberg J, et al. Cancer History and Risk Factors in Healthy Older People Enrolling in the ASPREE Clinical Trial. Contemp Clin Trials (2020) 96:106095. doi: 10.1016/ j.cct.2020.106095

41. Sung JJ, Ho JM, Lam AS, Yau ST, Tsoi KK. Use of Metformin and Aspirin is Associated With Delayed Cancer Incidence. Cancer Epidemiol (2020) 69:101808. doi: 10.1016/j.canep.2020.101808

42. Kang M, Ku JH, Kwak C, Kim HH, Jeong CW. Effects of Aspirin, Nonsteroidal Anti-Inflammatory Drugs, Statin, and COX2 Inhibitor on the Developments of Urological Malignancies: A Population-Based Study With 10-Year FollowUp Data in Korea. Cancer Res Treat (2018) 50:984-91. doi: 10.4143/ crt.2017.248

43. Stegeman I, Bossuyt PM, Yu T, Boyd C, Puhan MA. Aspirin for Primary Prevention of Cardiovascular Disease and Cancer. A Benefit and Harm Analysis. PloS One (2015) 10:e0127194. doi: 10.1371/journal.pone.0127194

44. Brasky TM, Liu J, White E, Peters U, Potter JD, Walter RB, et al. NonSteroidal Anti-Inflammatory Drugs and Cancer Risk in Women: Results From the Women's Health Initiative. Int J Cancer (2014) 135:1869-83. doi: 10.1002/ ijc. 28823

45. Jacobs EJ, Thun MJ, Bain EB, Rodriguez C, Henley SJ, Calle EE. A Large Cohort Study of Long-Term Daily Use of Adult-Strength Aspirin and Cancer Incidence. J Natl Cancer Inst (2007) 99:608-15. doi: 10.1093/jnci/djk132

46. Friis S, Sørensen HT, McLaughlin JK, Johnsen SP, Blot WJ, Olsen JH. A Population-Based Cohort Study of the Risk of Colorectal and Other Cancers Among Users of Low-Dose Aspirin. Br J Cancer (2003) 88:684-8. doi: $10.1038 /$ sj.bjc. 6600760
47. Pommer W, Bronder E, Klimpel A, Helmert U, Greiser E, Molzahn M. Urothelial Cancer at Different Tumour Sites: Role of Smoking and Habitual Intake of Analgesics and Laxatives. Results of the Berlin Urothelial Cancer Study. Nephrol Dial Transplant (1999) 14:2892-7. doi: 10.1093/ndt/ 14.12.2892

48. Wessels F, Kriegmair MC, Oehme A, Rassweiler-Seyfried MC, Erben P, Oberneder R, et al. Radical Cystectomy Under Continuous Antiplatelet Therapy With Acetylsalicylic Acid. Eur J Surg Oncol (2019) 45:1260-5. doi: 10.1016/j.ejso.2019.02.023

49. Prader R, De Broca B, Chevallier D, Amiel J, Durand M. Outcome of Transurethral Resection of Bladder Tumor: Does Antiplatelet Therapy Really Matter? Analysis of a Retrospective Series. J Endourol (2017) 31:1284-8. doi: 10.1089/end.2017.0587

50. Ghali F, Moses RA, Raffin E, Hyams ES. What Factors are Associated With Unplanned Return Following Transurethral Resection of Bladder Tumor? An Analysis of a Large Single Institution's Experience. Scand J Urol (2016) 50:370-3. doi: 10.1080/21681805.2016.1201856

51. Picozzi S, Marenghi C, Ricci C, Bozzini G, Casellato S, Carmignani L. Risks and Complications of Transurethral Resection of Bladder Tumor Among Patients Taking Antiplatelet Agents for Cardiovascular Disease. Surg Endosc (2014) 28:116-21. doi: 10.1007/s00464-013-3136-8

52. Ratnasinghe LD, Graubard BI, Kahle L, Tangrea JA, Taylor PR, Hawk E. Aspirin Use and Mortality From Cancer in a Prospective Cohort Study. Anticancer Res (2004) 24:3177-84.

53. Boorjian SA, Berglund RK, Maschino AC, Savage CJ, Herr HW. Fibrin Clot Inhibitor Medication and Efficacy of Bacillus Calmette-Guerin for Bladder Urothelial Cancer. J Urol (2009) 182:1306-12. doi: 10.1016/j.juro.2009.06.026

54. Gupta R, Das RK, Gupta S, Choudhary A, Basu S, Deb PP, et al. Role of Aspirin in Patients With Bladder Cancer Receiving Intravesical BCG: A Prospective, Observational Study. J Clin Diagn Res (2017) 11(10):PC01-4. doi: $10.7860 / \mathrm{JCDR} / 2017 / 31588.10690$

55. Gee JR, Jarrard DF, Bruskewitz RC, Moon TD, Hedican SP, Leverson GE, et al. Reduced Bladder Cancer Recurrence Rate With Cardioprotective Aspirin After Intravesical Bacille Calmette-Guérin. BJU Int (2009) 103:736-9. doi: 10.1111/j.1464-410X.2008.08123.x

56. Jacobs EJ, Newton CC, Gapstur SM, Thun MJ. Daily Aspirin Use and Cancer Mortality in a Large US Cohort. J Natl Cancer Inst (2012) 104:1208-17. doi: 10.1093 /jnci/djs318

57. Lipsky MJ, Badalato GM, Motamedinia P, Hruby GW, McKiernan JM. The Effect of Fibrin Clot Inhibitors on the Immunomodulatory Efficacy of Bacillus Calmette-Guérin Therapy for non-Muscle-Invasive Bladder Cancer. Urology (2013) 81:1273-8. doi: 10.1016/j.urology.2012.09.065

58. Singla N, Haddad AQ, Passoni NM, Meissner M, Lotan Y. Anti-Inflammatory Use may Not Negatively Impact Oncologic Outcomes Following Intravesical BCG for High-Grade non-Muscle-Invasive Bladder Cancer. World J Urol (2017) 35:105-11. doi: 10.1007/s00345-016-1853-z

59. Lyon TD, Frank I, Shah PH, Tarrell R, Cheville JC, Karnes RJ, et al. The Association of Aspirin Use With Survival Following Radical Cystectomy. J Urol (2018) 200:1014-21. doi: 10.1016/j.juro.2018.05.119

60. Li P, Ning Y, Li M, Cai P, Siddiqui AD, Liu EY, et al. Aspirin Is Associated With Reduced Rates of Venous Thromboembolism in Older Patients With Cancer. J Cardiovasc Pharmacol Ther (2020) 25:456-65. doi: 10.1177/ 1074248420925021

61. Pastore A, Palleschi G, Fuschi A, Silvestri L, Al Salhi Y, Costantini E, et al. Can Daily Intake of Aspirin and/or Statins Influence the Behavior of non-Muscle Invasive Bladder Cancer? A Retrospective Study on a Cohort of Patients Undergoing Transurethral Bladder Resection. BMC Cancer (2015) 15:120. doi: 10.1186/s12885-015-1152-x

62. Drew DA, Cao Y, Chan AT. Aspirin and Colorectal Cancer: The Promise of Precision Chemoprevention. Nat Rev Cancer (2016) 16:173-86. doi: 10.1038/ nrc.2016.4

63. Cheung KS, Chan EW, Wong A, Chen L, Seto WK, Wong I, et al. Aspirin and Risk of Gastric Cancer After Helicobacter Pylori Eradication: A TerritoryWide Study. J Natl Cancer Inst (2018) 110:743-9. doi: 10.1093/jnci/djx267

64. Simon TG, Ma Y, Ludvigsson JF, Chong DQ, Giovannucci EL, Fuchs CS, et al. Association Between Aspirin Use and Risk of Hepatocellular Carcinoma. JAMA Oncol (2018) 4:1683-90. doi: 10.1001/jamaoncol.2018.4154 
65. Skelin M, Javor E, Lucijanic M. Aspirin Use and the Risk of Cancer. JAMA Oncol (2019) 5:912-3. doi: 10.1001/jamaoncol.2019.0611

66. Matsumoto T, Shiina H, Kawano H, Sato T, Kato S. Androgen Receptor Functions in Male and Female Physiology. J Steroid Biochem Mol Biol (2008) 109:236-41. doi: 10.1016/j.jsbmb.2008.03.023

67. Li Y, Izumi K, Miyamoto $\mathrm{H}$. The Role of the Androgen Receptor in the Development and Progression of Bladder Cancer. Jpn J Clin Oncol (2012) 42:569-77. doi: $10.1093 /$ jjco/hys072

68. Sanguedolce F, Cormio L, Carrieri G, Calò B, Russo D, Menin A, et al. Role of Androgen Receptor Expression in non-Muscle-Invasive Bladder Cancer: A Systematic Review and Meta-Analysis. Histol Histopathol (2020) 35:423-32. doi: 10.14670/HH-18-189

69. Godoy G, Gakis G, Smith CL, Fahmy O. Effects of Androgen and Estrogen Receptor Signaling Pathways on Bladder Cancer Initiation and Progression. Bladder Cancer (2016) 2:127-37. doi: 10.3233/BLC-160052

70. Santella C, Rouette J, Brundage MD, Filion KB, Azoulay L. Androgen Deprivation Therapy for Prostate Cancer and the Risk of Bladder Cancer: A Systematic Review of Observational Studies. Urol Oncol (2020) 38:816-25. doi: 10.1016/j.urolonc.2020.04.028

71. Bilani N, Bahmad H, Abou-Kheir W. Prostate Cancer and Aspirin Use: Synopsis of the Proposed Molecular Mechanisms. Front Pharmacol (2017) 8:145. doi: 10.3389/fphar.2017.00145

72. Garland LL, Guillen-Rodriguez J, Hsu CH, Yozwiak M, Zhang HH, Alberts DS, et al. Effect of Intermittent Versus Continuous Low-Dose Aspirin on Nasal Epithelium Gene Expression in Current Smokers: A Randomized, Double-Blinded Trial. Cancer Prev Res (Phila) (2019) 12:809-20. doi: 10.1158/1940-6207.CAPR-19-0036

73. Wang X, Chan AT, Slattery ML, Chang-Claude J, Potter JD, Gallinger S, et al. Influence of Smoking, Body Mass Index, and Other Factors on the Preventive Effect of Nonsteroidal Anti-Inflammatory Drugs on Colorectal Cancer Risk. Cancer Res (2018) 78:4790-9. doi: 10.1158/0008-5472.CAN-18-0326

74. Slattery ML, Lundgreen A, Hines LM, Torres-Mejia G, Wolff RK, Stern MC, et al. Genetic Variation in the JAK/STAT/SOCS Signaling Pathway Influences Breast Cancer-Specific Mortality Through Interaction With Cigarette Smoking and Use of Aspirin/NSAIDs: The Breast Cancer Health Disparities Study. Breast Cancer Res Treat (2014) 147:145-58. doi: 10.1007/s10549-0143071-y

75. Wallace K, Grau MV, Ahnen D, Snover DC, Robertson DJ, Mahnke D, et al. The Association of Lifestyle and Dietary Factors With the Risk for Serrated Polyps of the Colorectum. Cancer Epidemiol Biomarkers Prev (2009) 18:23107. doi: 10.1158/1055-9965.EPI-09-0211

76. Levine PH. An Acute Effect of Cigarette Smoking on Platelet Function. A Possible Link Between Smoking and Arterial Thrombosis. Circulation (1973) 48:619-23. doi: 10.1161/01.cir.48.3.619

77. Arredondo J, Chernyavsky AI, Jolkovsky DL, Pinkerton KE, Grando SA. Receptor-Mediated Tobacco Toxicity: Cooperation of the Ras/Raf-1/MEK1/ ERK and JAK-2/STAT-3 Pathways Downstream of Alpha7 Nicotinic Receptor in Oral Keratinocytes. FASEB J (2006) 20:2093-101. doi: 10.1096/ fj.06-6191com

78. Veninga A, De Simone I, Heemskerk J, Cate HT, van der Meijden P. Clonal Hematopoietic Mutations Linked to Platelet Traits and the Risk of
Thrombosis or Bleeding. Haematologica (2020) 105:2020-31. doi: 10.3324/ haematol.2019.235994

79. Rocca B, Rubboli A, Zaccardi F. Antithrombotic Therapy and Revascularisation Strategies in People With Diabetes and Coronary Artery Disease. Eur J Prev Cardiol (2019) 26:92-105. doi: 10.1177/2047487319880045

80. Ishii M, Kaikita K, Sakamoto K, Seki T, Kawakami K, Nakai M, et al. Characteristics and in-Hospital Mortality of Patients With Myocardial Infarction in the Absence of Obstructive Coronary Artery Disease in SuperAging Society. Int J Cardiol (2020) 301:108-13. doi: 10.1016/j.ijcard.2019.09.037

81. Whitney DG, Peterson MD. The Association Between Differing Grip Strength Measures and Mortality and Cerebrovascular Event in Older Adults: National Health and Aging Trends Study. Front Physiol (2018) 9:1871. doi: 10.3389/ fphys.2018.01871

82. Figgins E, Choi YH, Speechley M, Montero-Odasso M. Associations Between Potentially Modifiable and Non-Modifiable Risk Factors and Gait Speed in Middle and Older-Aged Adults: Results From the Canadian Longitudinal Study on Aging. J Gerontol A Biol Sci Med Sci (2021) glab008. doi: 10.1093/ gerona/glab008

83. Czachorowski MJ, Amaral AF, Montes-Moreno S, Lloreta J, Carrato A, Tardón A, et al. Cyclooxygenase-2 Expression in Bladder Cancer and Patient Prognosis: Results From a Large Clinical Cohort and Meta-Analysis. PloS One (2012) 7:e45025. doi: 10.1371/journal.pone.0045025

84. Fan B, Zhang H, Jin H, Gai Y, Wang H, Zong H, et al. Is Overexpression of Ki67 a Prognostic Biomarker of Upper Tract Urinary Carcinoma? A Retrospective Cohort Study and Meta-Analysis. Cell Physiol Biochem (2016) 40:1613-25. doi: 10.1159/000453211

85. Rao KV, Detrisac CJ, Steele VE, Hawk ET, Kelloff GJ, McCormick DL. Differential Activity of Aspirin, Ketoprofen and Sulindac as Cancer Chemopreventive Agents in the Mouse Urinary Bladder. Carcinogenesis (1996) 17:1435-8. doi: 10.1093/carcin/17.7.1435

86. Goodman B, Gardner H. The Microbiome and Cancer. J Pathol (2018) 244:667-76. doi: 10.1002/path.5047

87. Yang $\mathrm{Y}$, Misra $\mathrm{BB}$, Liang $\mathrm{L}, \mathrm{Bi} \mathrm{D}$, Weng $\mathrm{W}, \mathrm{Wu} \mathrm{W}$, et al. Integrated Microbiome and Metabolome Analysis Reveals a Novel Interplay Between Commensal Bacteria and Metabolites in Colorectal Cancer. Theranostics (2019) 9:4101-14. doi: 10.7150/thno.35186

88. Miller KD, Goding Sauer A, Ortiz AP, Fedewa SA, Pinheiro PS, TortoleroLuna G, et al. Cancer Statistics for Hispanics/Latinos, 2018. CA Cancer J Clin (2018) 68:425-45. doi: 10.3322/caac.21494

Conflict of Interest: The authors declare that the research was conducted in the absence of any commercial or financial relationships that could be construed as a potential conflict of interest.

Copyright $\odot 2021$ Fan, Mohammed, Huang, Luo, Zhang, Tao, Xu, Liu, He, Jin, Sun, Sun, Yun, Zhao, Wu and Li. This is an open-access article distributed under the terms of the Creative Commons Attribution License (CC BY). The use, distribution or reproduction in other forums is permitted, provided the original author(s) and the copyright owner(s) are credited and that the original publication in this journal is cited, in accordance with accepted academic practice. No use, distribution or reproduction is permitted which does not comply with these terms. 